Check for updates

Cite this: RSC Adv., 2018, 8, 262

Received 22nd November 2017 Accepted 14th December 2017

DOI: 10.1039/c7ra12687e

rsc.li/rsc-advances

\section{Hexafluorophosphate salts with tropine-type cations in the extraction of alkaloids with the same nucleus from radix physochlainae $\uparrow$}

\begin{abstract}
Bing Dong, Jie Tang, Alula Yonannes and Shun Yao iD *
Ionic liquids (ILs) have been widely used in the field of extraction of natural bioactive compounds because of their advantages compared to traditional organic solvents. In this study, the new 'like dissolves like' mode was designed and seven types of tropine-based ionic liquids were used to extract tropane alkaloids from radix physochlainae, and then the relationship between their performance and structures together with the effects of main extraction conditions were explored. It was found that $0.05 \mathrm{~mol} \mathrm{~L} \mathrm{~L}^{-1}\left[\mathrm{C}_{3} \mathrm{tr}\right]\left[\mathrm{PF}_{6}\right]$ aqueous solution had the ideal selectivity and high extraction efficiency of $95.1 \%$ at $75{ }^{\circ} \mathrm{C}$ when the extraction time was $55 \mathrm{~min}$ and the solid-liquid ratio was 1 : 35, which was superior to that of $85 \%$ ethanol-water and $0.1 \%$ hydrochloric acid-water. There was no decomposition and racemization of products occurring in the mixture solution when above extraction solvent was applied. In addition, the extraction behavior and mechanism using an ionic liquid aqueous solution was tentatively studied through thermodynamics experiments, near-infrared/infrared spectroscopy (NIR/IR), scanning electron microscopy (SEM), and thermogravimetric analysis (TG), and subsequent back-extraction could be efficiently used to further separate alkaloids and ILs. In the developed 'like dissolves like' mode, the extraction process of target alkaloids was found to be endothermic and spontaneous through the specific interaction between them and the solvent molecules with the same nucleus.
\end{abstract}

\section{Introduction}

Radix physochlainae is the dried root of Physochlainae infundibularis Kuang (Solanaceae), which has been used for a very long time in China and has been officially listed in the Chinese Pharmacopoeia. ${ }^{1}$ It has the unique curative effects of relieving coughs and asthma as a traditional herbal medicine. The tropane series of alkaloids in radix physochlainae mainly include five kinds of alkaloids (anisodamine, scopolamine, atropine, scopoline and aposcopolamine), which are widely used for the treatment of expectorant, antiasthmatic, antitussive and diseases of the central nervous system. ${ }^{2}$ In a previous study, Peng and coworkers ${ }^{3}$ used $75 \%$ ethanol to extract total tropane alkaloids from flos daturae with final yield of $0.32 \%$ through a twice soaking extraction ( $75 \mathrm{~h}$ every time) and a yield of $0.38 \%$ through twice backflow extraction $(2 \mathrm{~h}+1.5 \mathrm{~h})$. In another study, a microwave-assisted method was employed and $87 \%$ tropane alkaloids was extracted under the conditions if $1: 10$ solid-liquid ratio (w/v), $25 \mathrm{~min}, 730 \mathrm{~W}$ microwave power and $65{ }^{\circ} \mathrm{C} .{ }^{4}$ Ultrasonic wave $(40 \mathrm{~Hz})$ assisted extraction was also adopted by researchers ${ }^{5}$ and the yield of $0.44 \%$ was finally

School of Chemical Engineering, Sichuan University, Chengdu, 610065, China. E-mail: cusack@scu.edu.cn; Fax: +86-028-85405221; Tel: +86-028-85405221

$\dagger$ Electronic supplementary information (ESI) available. See DOI: $10.1039 / \mathrm{c} 7 \mathrm{ra} 12687 \mathrm{e}$ obtained when the extraction was carried out with $85 \%$ ethanol on $50{ }^{\circ} \mathrm{C}$ for $75 \mathrm{~min}$. However, there are some problems including long extraction time, low efficiency and high consumption in the traditional reflux or immersing extraction. On the other hand, new technologies such as ultrasonic extraction and microwave extraction cannot be easily applied to large-scale production in industry because of the limitations of devices and high cost. More importantly, no matter what kind of these mentioned methods is used, traditional alcohol-water/ acid-water solvent system will extract most of constituents in herbs without high selectivity, and the great amount of coexisting impurities can result in the difficulty of obtaining target compounds. Therefore, it is necessary to develop more new extraction methods that can promote extraction selectivity, efficiency and practicability meanwhile overcome the problems resulting from the use of traditional solvents.

'Like dissolves like' is a very classical expression frequently used by chemists to understand how some solvents work in the dissolution of solutes. It is generally recognized that this view is simplistic meanwhile it is a useful rule of thumb. The overall solvation capacity of a solvent depends primarily on its polarity. In the field of liquid-phase extraction and liquid-liquid partition, the rule of 'like dissolves like' generally refers to that target compounds tend to dissolve in the solvents with similar polarity. Guided by this rule, researchers can select a series of potential solvents for specific objects on the basis of 
accumulated experience and then compare their performance through further experiments. More researches are expected for their valuable contribution to develop new theories and explore deep mechanism, especially for the results when the target compounds meet the extractants with similar structures. Ionic liquids (ILs) is such a kind of designable solvents with variable structures, which have a lot of unique properties (e.g. high solubility, vapor pressure, and good stability, etc.) different from those of volatile organic solvents (VOS). ${ }^{6}$ They are attracting more and more attention from researchers in the fields of organic synthesis, catalysis and separation science. ${ }^{7-9}$ In recent years, ionic liquids have been widely used in the field of extraction and separation of natural products; they can competitively generate hydrogen bonds with cellulose for the maximum damage to the $\mathrm{H}$-bonding network of cellulose microfibrils, which makes them more easily enter into the plant cell and improve the extraction efficiency. In addition, the solubility of ILs and their specific interactions with different objects can be regulated by adjusting the combination of anions and cations. Finally, the ionic liquid also can be applied in ultrasonic and microwave-assisted modes to shorten the extraction time and promote the extraction efficiency, which is very meaningful in the protection of natural products from destruction under severe conditions. For instance, Cao and his workers ${ }^{10}$ used a series of 1-alkyl-3-methylimidazolium ionic liquids to extract piperine from white pepper powders with ultrasonic wave, and they found that the increase of ILs hydrophilicity was beneficial for the improvement of extraction yield. Therefore the yield of $35.7 \mathrm{mg} \mathrm{g}^{-1}$ was obtained by $2 \mathrm{~mol} \mathrm{~L}^{-1}$ [BMIM] $\left[\mathrm{BF}_{4}\right]$ after $30 \mathrm{~min}$ in $500 \mathrm{~W}$ ultrasonic wave, meanwhile only $19.60 \mathrm{mg} \mathrm{g}^{-1}$ yield could be achieved by $75 \%$ methanol. Ma and his workers ${ }^{11}$ developed microwave-assisted extraction to obtain three alkaloids from lotus leaves. The extraction efficiency of [BMIM] $[\mathrm{Br}]$ was highest compared with other six kinds of ILs because its acidity was more conducive to generate salts with alkaloids, and the yield of three alkaloids by using [BMIM] [Br] were all higher than that of $80 \%$ ethanol. The research group of $\mathrm{Zu}$ found that the extraction efficiency of ILs for three alkaloids from Catharanthus roseus increased when the alkyl chain length of the cation was changed from $\mathrm{C}_{2}$ to $\mathrm{C}_{8},{ }^{12}$ which was due to the hydrophobic effect between ionic liquids and alkaloids and it became the main driving force in the extraction process. In summary, most of these studies focused on the application of ionic liquids in existing extraction modes. Their structural designability is always underutilized and related advantages cannot be fully exploited. Moreover, the inner relationship between their unique physicochemical properties and extraction performance needs further exploration.

According to above research status, the rule of 'like dissolves like' can be simply interpreted as that the hydrophilic cations or anions are needed when the extracted alkaloids are low-polar. At a deeper level, since the formation of hydrogen bonds, dipoledipole interaction, van der Waals' force and Coulomb force between the ionic liquid and alkaloids can strengthen the selective recognition ability of IL and promote their binding; those ILs with the same nucleus with alkaloids should be more suitable and efficient in the extraction of the latter. This hypothesis is supposed to be the generalized 'like dissolves like' rule, which will be further evaluated and validated in the following study. Here radix physochlainae was selected as typical herbal object containing tropane alkaloids, and seven kinds of tropane-types ionic liquids were used to extract target alkaloids from it in this new mode. Accordingly, the major research objectives are focused on as followings: (1) what will happen when alkaloids meet the ILs with similar structure? (2) Will the "like dissolve like" rule work on the basis of structural similarity? (3) Can high efficiency and selectivity be obtained when the ILs interact with their analogues in such a complex composition from herbal sample? Related main properties of ionic liquids were first explored, and then the extraction conditions were investigated and the extraction mechanism using ionic liquid aqueous solution was studied. Obviously, this reinterpreted rule can maximize the ILs advantages of designability and selectivity, while it cannot be made full use by those common undesignable solvents.

\section{Experiment}

\subsection{Materials}

Herbal raw materials of radix physochlainae originating in Shaanxi province were obtained from local pharmacy and identified as the dried roots of the Solanaceae plant by Prof. Fangyan Li in our department. They were milled and dried and then the sample powders passed through a stainless steel sieve with the particle size of 60 mesh. All chemicals involved in this study were at least of analytical grade and purchased from Kelong Chemical reagents factory (Chengdu, China). Chromatographic methanol used for high performance liquid chromatography (HPLC) was purchased from Chengdu Chemical reagents factory and filtered with microporous membrane $(0.45 \mu \mathrm{m})$ before use. Standard compounds of anisodamine, $\mathrm{D} / \mathrm{L}-$ atropine, scopolamine, aposcopolamine and scopoline (see Fig. 1) used for HPLC were purchased from National Food and Drug Inspection Institute (Beijing, China) or Research Chemicals Inc. (Toronto, Canada) and all of their purities $\geq 98.0 \%$. Experimental deionized water was obtained from ultra-pure water purification system $(0.4 \mathrm{~mm}$ filter $)$ manufactured by Millipore Co., Ltd. (Bedford, USA). Ionic liquids in Fig. 1 were synthesized and purified according to the previous method, ${ }^{13}$ and the purity (all above 97.9\%) was analyzed by HPLC method with evaporative light-scattering detector. All samples were stored in closed desiccators until use.

\subsection{Apparatus}

Nicolet 6700 Fourier transform infrared spectrometer (Abbre. FT-IR, Thermo Scientific, Madison, USA), JSM-7001F scanning electron microscopy (Abbre. SEM, JEOL, Tokyo, Japan), STA 449 F3 simultaneous thermal analyzer (NETZSCH, Selb, Germany) were used to observe morphology of herbal powders and residue after extraction. NIR spectrometer (NIRQUEST512), deuterium light source (DH-2000-BAL) and fiber optic probes (T300-UVVIS) were provided by Ocean Optics (Dunedin, USA), which 


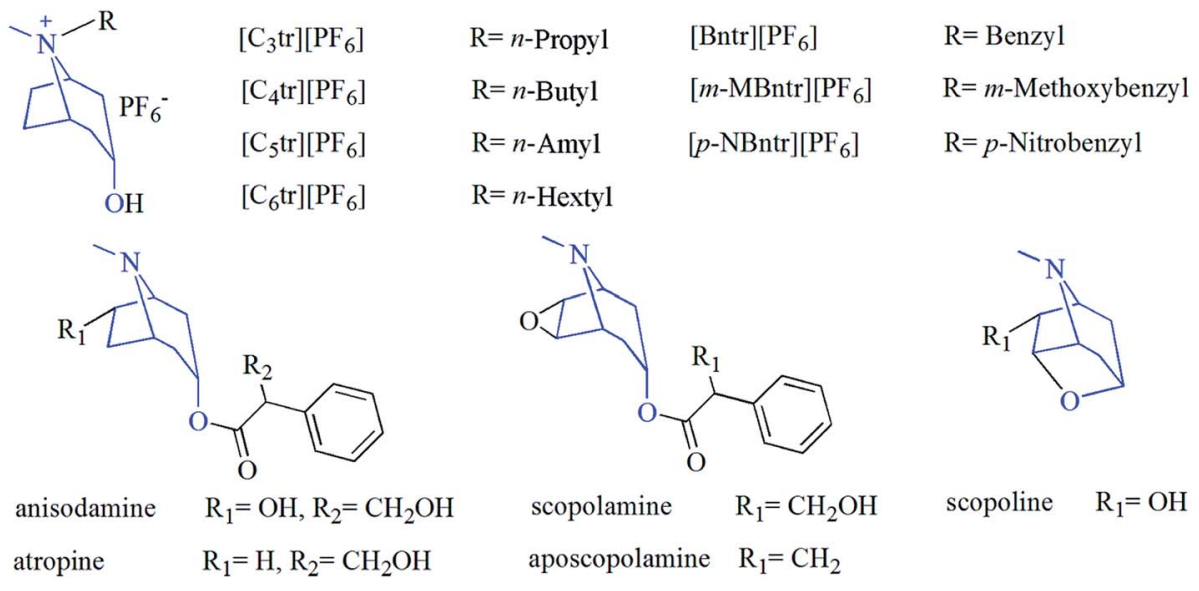

Fig. 1 Structures of tropane alkaloids and hexafluorophosphate salts with same nucleus.

was used to detect the extraction of alkaloids from radix physochlainae. Extraction experiments were carried out using HH-S constant temperature water bath with an uncertainty of $\pm 0.05 \mathrm{~K}$ (Wanke Instrumental Co. Ltd., Jiangsu, China) and KQ-2200DA ultrasonic extractor (Shumei Co. Ltd., Jiangsu, China). DDS-12A conductivity meter (Kangyi Scientific instrument Co. Ltd., Shanghai, China) and 2800 UV-Vis spectrometer (Hengping instrument Co. Ltd., Shanghai, China) were used to measure conductivity and polarity of ionic liquids. HPLC analysis was performed with EC2006 HPLC (Elite, Dalian, China) consisting of UV1201 UV-Vis detector and ELSD 2000 evaporative light-scattering detector (Alltech, Kentucky, USA). Refractive index of alkaloids extraction solution was determined by WAY-2S Abbe refractometer (Shenguang instrument Co., Ltd., Shanghai, China) to study thermodynamics and dynamics of alkaloids extracted from radix physochlainae.

\subsection{Determination of ionic liquid polarity and conductivity}

The polarity of ionic liquids was measured by Reichardt's dye method $^{14}$ as following: $2.5 \mathrm{~g}$ ionic liquids were accurately weighed and dissolved in $100 \mathrm{~mL}$ of methanol, then $0.0375 \mathrm{~g}$ 2,6-diphenyl-4-(2,4,6-triphenyl- $N$-pyridino)phenolate was added into above IL methanol solution. When the dye molecule was completely dissolved and mixed with the ionic liquids, methanol in the mixture was completely removed under vacuum for $48 \mathrm{~h}$, and then the dried product was analyzed by full wavelength scanning (200-800 nm). Conductivity was measured using DDS-12A digital conductivity meter with automatic balance bridge, and the conductance electrode constant was determined as $1.0474 \mathrm{~cm}^{-1}$ by standard aqueous solution potassium chloride $\left(0.01 \mathrm{~mol} \mathrm{~L}^{-1}\right)$. Seven kinds of ionic liquids were measured from $5{ }^{\circ} \mathrm{C}$ to $85{ }^{\circ} \mathrm{C}$ with interval of $20{ }^{\circ} \mathrm{C}$ under stirring to reach complete equilibrium. The electrode and conductivity cell with self-made double jacketed glass device were washed with distilled water, redistilled water and acetone respectively, and then dried by cold air before the measurement.

\subsection{Extraction procedure}

2.4.1 Extraction by ionic liquids aqueous solution. $1.00 \mathrm{~g}$ powders (60 meshes) of radix physochlainae were weighed accurately and placed in $50 \mathrm{~mL}$ Erlenmeyer flask, which was mixed with $10 \mathrm{~mL} 0.05 \mathrm{~mol} \mathrm{~L}^{-1}$ aqueous solution of hexafluorophosphate salt $(\mathrm{pH}=5.3)$. The target constituents were extracted at $70{ }^{\circ} \mathrm{C}$ in constant temperature water bath for a certain time. At the end of extraction, the solution was filtered and the filtrate was concentrated and its volume was set with methanol of chromatographic grade to $5 \mathrm{~mL}$. Then the sample solution was filtered with a microporous membrane of $0.45 \mu \mathrm{m}$ before HPLC analysis.

2.4.2 Extraction by traditional solvents. Four common solvents were selected to extract the target alkaloids from the same powders (60 meshes) of radix physochlainae with comparison to ionic liquids, which included pure deionized water (1), the system of $0.1 \%$ hydrochloric acid and water (2), the mixture of $85 \%$ ethanol and water (3), and the system of $85 \%$ ethanol and $0.1 \%$ hydrochloric acid with water (4). The extraction was carried out with solid-liquid ratio $\left(\mathrm{g} \mathrm{mL}^{-1}\right)$ of $1: 10$ at $70{ }^{\circ} \mathrm{C}$ for $50 \mathrm{~min}$; after extraction, the solution was filtered and the filtrate was evaporated and then diluted with methanol of chromatographic grade to $10 \mathrm{~mL}$. Various samples were filtered with $0.45 \mu \mathrm{m}$ microporous membrane and the content of total alkaloids was analyzed by HPLC to calculate extraction efficiency (\%).

\subsection{Analytical method}

2.5.1 HPLC conditions and standard curves of five alkaloids. HPLC analysis based on the reported method ${ }^{15}$ for five representative alkaloids was carried out on Welch $\mathrm{C}_{18}$ chromatographic column $(4.6 \times 250 \mathrm{~mm}, 5 \mu \mathrm{m})$ at column temperature of $25{ }^{\circ} \mathrm{C}$; the mobile phase was composed of $20 \mathrm{mmol} \mathrm{L}^{-1}$ ammonium acetate solution (A) and methanol (B) and the flow rate was $1.0 \mathrm{~mL} \mathrm{~min}{ }^{-1}$. Detection wavelength was set at $210 \mathrm{~nm}$ and injection volume was $5 \mu \mathrm{L}$, and the gradient procedure was operated as: 0-10 $\mathrm{min}, \mathrm{A}: \mathrm{B}=60: 40(\mathrm{v} / \mathrm{v}) ; 10-$ $30 \mathrm{~min}, \mathrm{~A}: \mathrm{B}=30: 70(\mathrm{v} / \mathrm{v})$; after $30 \mathrm{~min}, \mathrm{~A}: \mathrm{B}=20: 80(\mathrm{v} / \mathrm{v})$. 
The concentration of five standard alkaloids had good linear relationship with peak area in the investigated range of content, and corresponding standard curves of anisodamine, atropine, scopolamine, aposcopolamine and scopoline were determined as $y_{1}=12261.40 x_{1}-368.19\left(R^{2}=0.9998\right.$, linear range: $0.50-$ $3.50 \mu \mathrm{g}, 95 \%$ confidence interval of slope and intercept: $\pm 152.80 \& 4.26), y_{2}=3560.60 x_{2}-619.55\left(R^{2}=0.9997\right.$, linear range: $0.24-1.28 \mu \mathrm{g}, 95 \%$ confidence interval of slope and intercept: $\pm 38.21 \& 8.08), y_{3}=1628.80 x_{3}-135.65\left(R^{2}=0.9999\right.$, linear range: $0.17-1.73 \mu \mathrm{g}, 95 \%$ confidence interval of slope and intercept: $\pm 17.98 \& 2.53), y_{4}=2188.80 x_{4}-266.52\left(R^{2}=0.9997\right.$, linear range: $0.15-0.40 \mu \mathrm{g}, 95 \%$ confidence interval of slope and intercept: $\pm 23.17 \& 4.32), y_{5}=110.59 x_{5}-1.84\left(R^{2}=0.9998\right.$, linear range: $0.20-1.20 \mu \mathrm{g}, 95 \%$ confidence interval of slope and intercept: $\pm 1.98 \& 0.09)$ successively, where $x$ was their amount $(\mu \mathrm{g})$ and $y$ was the UV absorbance value of related peak area, respectively.

2.5.2 Quantitative analysis of tropane alkaloids in herbal material. $1.00 \mathrm{~g}$ powders (60 mesh) of radix physochlainae were weighed accurately and pretreated with ammonia, and then were extracted by chloroform with solid-liquid ratio of $1: 10(\mathrm{~g}$ $\mathrm{mL}^{-1}$ ) for 3 times. $^{16}$ The extract was concentrated and its volume was set with methanol to $10 \mathrm{~mL}$, and $20 \mu \mathrm{L}$ sample solution was injected into HPLC after filtration by $0.45 \mu \mathrm{m}$ microporous membrane. As the result, the chromatogram of total extract from radix physochlainae indicated that five alkaloids could be separated well with other coexisting compounds (see Fig. 2a); their amount could be determined according to the peak area and standard curves introduced in the last section. It showed that anisodamine $\left(0.632 \mathrm{mg} \mathrm{g}^{-1}\right)$ and scopoline ( $\left.0.509 \mathrm{mg} \mathrm{g}^{-1}\right)$ are the first and second main alkaloids in our sample respectively, meanwhile the content of aposcopolamine was only $0.093 \mathrm{mg} \mathrm{g}^{-1}$ (shown in Fig. 2b) and total mass fraction of five alkaloids was $0.173 \%$ in herbal material. The amount of target constituents $\left(m_{1}, \mathrm{mg}\right)$ in extraction solution was obtained by the developed HPLC method and used to calculate the extraction efficiency (\%), which could be determined through the following equation:

$$
\text { Extraction efficiency }(E, \%)=\left(m_{1} / m_{0}\right) \times 100
$$

where $m_{0}(\mathrm{mg})$ is the total alkaloids amount in herbal powders determined as above.

\subsection{Mathematical tools}

2.6.1 First-order model. A general first-order model has been used to study the kinetics of solid-liquid extraction, which can provide an acceptable representation of solid-liquid extraction as evident. ${ }^{17,18}$ The parameters in the first order kinetic model can be easily elucidated from the extraction kinetics, using the analytical solution obtained by integral analysis. The same model has been extended to study the extraction of alkaloids from radix physochlainae by ionic liquids aqueous solution and other traditional organic solvents. The first order kinetic model can be represented as:

$$
\frac{\mathrm{d} C_{t}}{\mathrm{~d} t}=\kappa\left(C_{\mathrm{s}}-C_{t}\right)
$$

where $C_{t}\left(\mathrm{mg} \mathrm{mL}^{-1}\right)$ is the concentration of alkaloids at any time $(t), C_{\mathrm{s}}\left(\mathrm{mg} \mathrm{mL}^{-1}\right)$ is the saturation concentration of alkaloids and $k\left(\mathrm{~min}^{-1}\right)$ is the first order rate constant. Then eqn (2) is solved with the boundary conditions as $\left.C_{t}\right|_{t=0}=0$ and $\left.C_{t}\right|_{t=t}=C_{t}$ to be:

$$
\ln \left(C_{\mathrm{s}}-C_{t}\right)=\kappa t+A
$$

The effect of temperature on extraction rate constant provides information on the activation energy that must be overcome for extraction. The extraction rate constant is related to the activation energy $\left(E_{\mathrm{a}}\right)$ and temperature $(T)$ as following:

$$
\kappa=\kappa_{0} \times \mathrm{e}^{\frac{-E_{\mathrm{a}}}{R T}}
$$

where a plot of $\ln (\kappa) v s$. $1 / T$ yields a straight line with $\left(E_{\mathrm{a}} / R\right)$ as the slope, from which activation energy can be determined.

2.6.2 Effective diffusion coefficient of extraction of alkaloids from radix physochlainae. To study the effective diffusion coefficient of alkaloids from radix physochlainae, the diffusion (a)

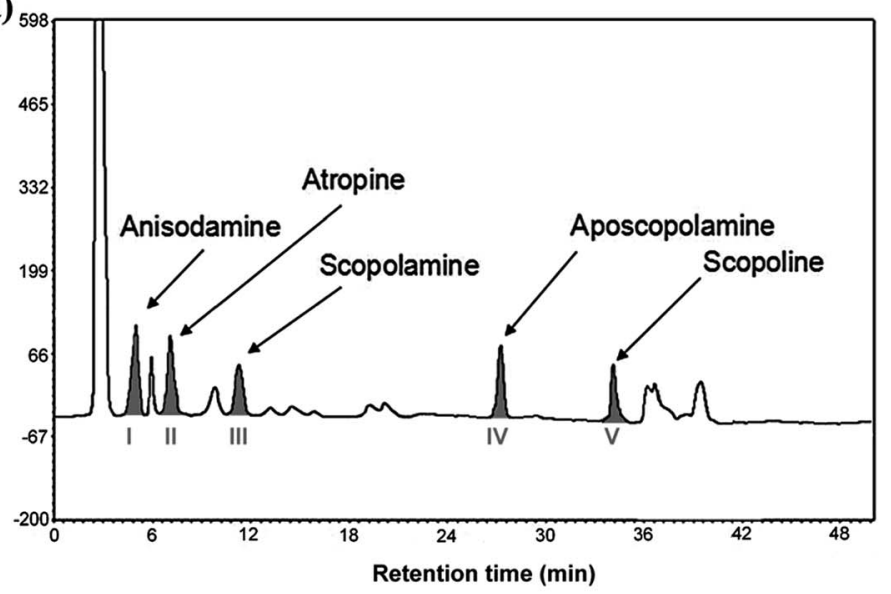

(b)

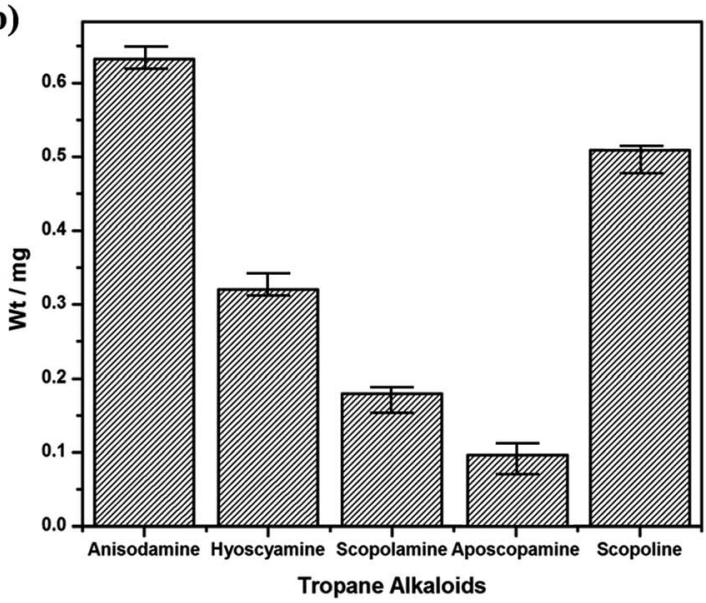

Fig. 2 The chromatogram (a) and composition (b) of five tropane alkaloids in radix physochlainae. 
model based on Fick's second law was used in this study. The law for extraction of alkaloids from spherical particles is expressed as following: ${ }^{19}$

$$
\frac{\partial M}{\partial t}=D_{\mathrm{e}}\left[\frac{1}{r^{2}} \frac{\partial}{\partial r}\left(r^{2} \frac{\partial M}{\partial r}\right)\right]
$$

where $M\left(\mathrm{~kg} \mathrm{~m}^{-3}\right)$ is the alkaloids concentration in radix physochlainae particles, $r(\mathrm{~m})$ is the distance from the center of herbal particles, $D_{\mathrm{e}}$ is the effective diffusion coefficient of alkaloids and $t$ (min) is time. According to the ref. 20, the solution of eqn (5) using the initial and boundary conditions can be transformed to:

$$
\frac{Y_{t}}{Y_{\mathrm{s}}}=1-\frac{6}{\pi^{2}} \exp \left(-\frac{D_{\mathrm{e}} \pi^{2} t}{R^{2}}\right)
$$

where $Y_{t}\left(\mathrm{mg} \mathrm{g}^{-1}\right)$ is the yield of total alkaloids extracted from radix physochlainae at time $(t), Y_{\mathrm{S}}\left(\mathrm{mg} \mathrm{g}^{-1}\right)$ is the yield of total alkaloids extracted at saturation. The effective diffusion coefficient can be calculated from time-yield data using eqn (6).

2.6.3 Thermodynamics of extraction of alkaloids from radix physochlainae. Thermodynamic analysis of extraction of solute from solid using extraction has been carried out through determination of $\Delta G^{\mathrm{o}}, \Delta H^{\mathrm{o}}$ and $\Delta S^{\mathrm{o}}$. Van't Hoff equation ${ }^{21}$ can be used to determine $\Delta G^{\mathrm{o}}$ and $\Delta S^{\mathrm{o}}$ as following:

$$
\ln K_{\mathrm{e}}=-\frac{\Delta H^{\mathrm{o}}}{R T}+\frac{\Delta S^{\mathrm{o}}}{R}
$$

where $K_{\mathrm{e}}$ is the equilibrium constant for leaching and is defined as the ratio of amount of extracted solute to that of unextracted solute. ${ }^{21}$ In the present case, it is the ratio of the amount of extracted alkaloids to the amount of unextracted alkaloids as given below:

$$
K_{\mathrm{e}}=\frac{Y_{\mathrm{s}}}{Y_{\max }-Y_{\mathrm{s}}}
$$

where $Y_{\mathrm{s}}\left(\mathrm{mg} \mathrm{g}^{-1}\right)$ is the total alkaloid yield extracted using ionic liquid aqueous solution as the solvent at a temperature $T(\mathrm{~K})$ and $Y_{\max }$ is the total alkaloid yield $\left(\mathrm{mg} \mathrm{g}^{-1}\right)$ determined after an exhaustive extraction using chloroform as the solvent. $\Delta G^{\mathrm{o}}$ is calculated from $\Delta H^{\mathrm{o}}$ and $\Delta S^{\mathrm{o}}$ as eqn (9): ${ }^{21}$

$$
\Delta G^{\mathrm{o}}=\Delta H^{\mathrm{o}}-T \Delta S^{\mathrm{o}}
$$

\section{Results and discussion}

\subsection{Structure, properties and extraction performance of ILS for tropane alkaloids}

The physical and chemical properties of ionic liquids can be significantly affected by the combination of cations and anions, ${ }^{22}$ so their extraction performance is very different for specific compounds. Generally, the structural features of target constituents and the special characteristics of ILs as polar organic salts should be fully considered before the extraction, and then the potential tropine-based ionic liquids are selected according to the generalized principle of 'like dissolves like' to achieve efficient and highly-selective extraction. Meanwhile, considering the lower polarity of tropane alkaloids, $\left[\mathrm{PF}_{6}\right]^{-}$was chosen as the most commonly used hydrophobic anion. As the result, seven ionic liquids were used to extract alkaloids with the same nucleus and the comparison of extraction efficiency was performed under the same extraction conditions of $0.1 \mathrm{~mol} \mathrm{~L}^{-1}$ ionic liquids aqueous solution, 1:10 solid-liquid ratio ( $\mathrm{g}$ $\mathrm{mL}^{-1}$ ), $50 \mathrm{~min}$ and $70{ }^{\circ} \mathrm{C}$. As shown in Fig. 3a, it can be found that the order of extraction efficiency is same as that of association constant of the studied ionic liquids (see Table 1), and both of them is $\left[\mathrm{C}_{3} \mathrm{tr}\right]\left[\mathrm{PF}_{6}\right]>\left[\mathrm{C}_{4} \mathrm{tr}\right]\left[\mathrm{PF}_{6}\right]>[m-\mathrm{MBntr}]\left[\mathrm{PF}_{6}\right]>\left[\mathrm{C}_{6} \mathrm{tr}\right]$ $\left[\mathrm{PF}_{6}\right]>\left[\mathrm{C}_{5} \mathrm{tr}\right]\left[\mathrm{PF}_{6}\right]>[p-\mathrm{NBntr}]\left[\mathrm{PF}_{6}\right]>[\mathrm{Bntr}]\left[\mathrm{PF}_{6}\right]$. Obviously, one of the key factors for high extraction efficiency is the strong association action resulting from intermolecular interactions between ionic liquids and alkaloids, and there are two competitive effects between ionic liquids-water and ionic liquids-alkaloids in extraction system. If the solvation of water for ionic liquids is weaker, the extraction efficiency will be higher because of the stronger association effect of ionic liquids with alkaloids. Here the association constant provides an ideal prediction index for the extraction performance of various ILs.

At the same time, the polarity of ionic liquids is also one of the important properties that affect the extraction rate of alkaloids. So it was investigated through the method described in Section 2.3 and the data have been reported in our previous study. ${ }^{13}$ As the result, the polarity of four kinds of ionic liquids branched with linear carbon chain were found higher than that with aromatic hydrocarbons except for $[p-\mathrm{NBntr}]\left[\mathrm{PF}_{6}\right],{ }^{23}$ which was due to that strong electron withdrawing group in [ $p$-NBntr] $\left[\mathrm{PF}_{6}\right]$ could make the charge center of the molecule more unevenly distributed and the molecular polarity of $[p$-NBntr] $\left[\mathrm{PF}_{6}\right]$ was higher than that of $\left[\mathrm{C}_{n} \mathrm{tr}\right]\left[\mathrm{PF}_{6}\right](n=5$ or 6$)$. Because the nonpolar alkyl chain is shorter, the polarity of $\left[\mathrm{C}_{3} \mathrm{tr}\right]\left[\mathrm{PF}_{6}\right]$ and $\left[\mathrm{C}_{4} \mathrm{tr}\right]\left[\mathrm{PF}_{6}\right]$ is higher than that of $\left[\mathrm{C}_{5} \mathrm{tr}\right]\left[\mathrm{PF}_{6}\right]$ and $\left[\mathrm{C}_{6} \mathrm{tr}\right]\left[\mathrm{PF}_{6}\right]$, and their extraction performance was found higher than the latter two ILs.

In the further investigation for inherent relationship between ILs and individual alkaloids with same nucleus, the extraction rule of four kinds of ionic liquids branched with linear carbon chain $\left(\mathrm{C}_{3} \sim \mathrm{C}_{6}\right)$ for anisodamine and scopoline was firstly studied (shown in Fig. 3b), which had the first and second highest content among these alkaloids. It was found that extraction rate of anisodamine became higher with the increase of polarity of ionic liquids, while the trend for scopoline was exactly the opposite. From the viewpoint of the 'like dissolves like' extraction for single alkaloid compound, it could be found that they can be extracted more efficiently when their polarity is more similar to the polarity of ILs. Anisodamine has more polar groups in its structure and shorter retention time in reverse-phase system than scopoline, which can indicate that the polarity of anisodamine is higher than that of the latter; so the high extraction efficiency of anisodamine and scopoline can be achieved by $\left[\mathrm{C}_{3} \mathrm{tr}\right]\left[\mathrm{PF}_{6}\right]$ as the IL with highest polarity and $\left[\mathrm{C}_{6} \mathrm{tr}\right]\left[\mathrm{PF}_{6}\right]$ as the IL with lowest polarity, respectively. Moreover, it should be noticed that $\left[\mathrm{C}_{3} \operatorname{tr}\right]\left[\mathrm{PF}_{6}\right]$ had higher efficiency than $\left[\mathrm{C}_{4} \mathrm{tr}\right]\left[\mathrm{PF}_{6}\right]$ for the extraction of scopoline, and this result was also attributed to the structure of the IL cation. Alkyl chain with the carbon number $<4$ is more beneficial for intermolecular 

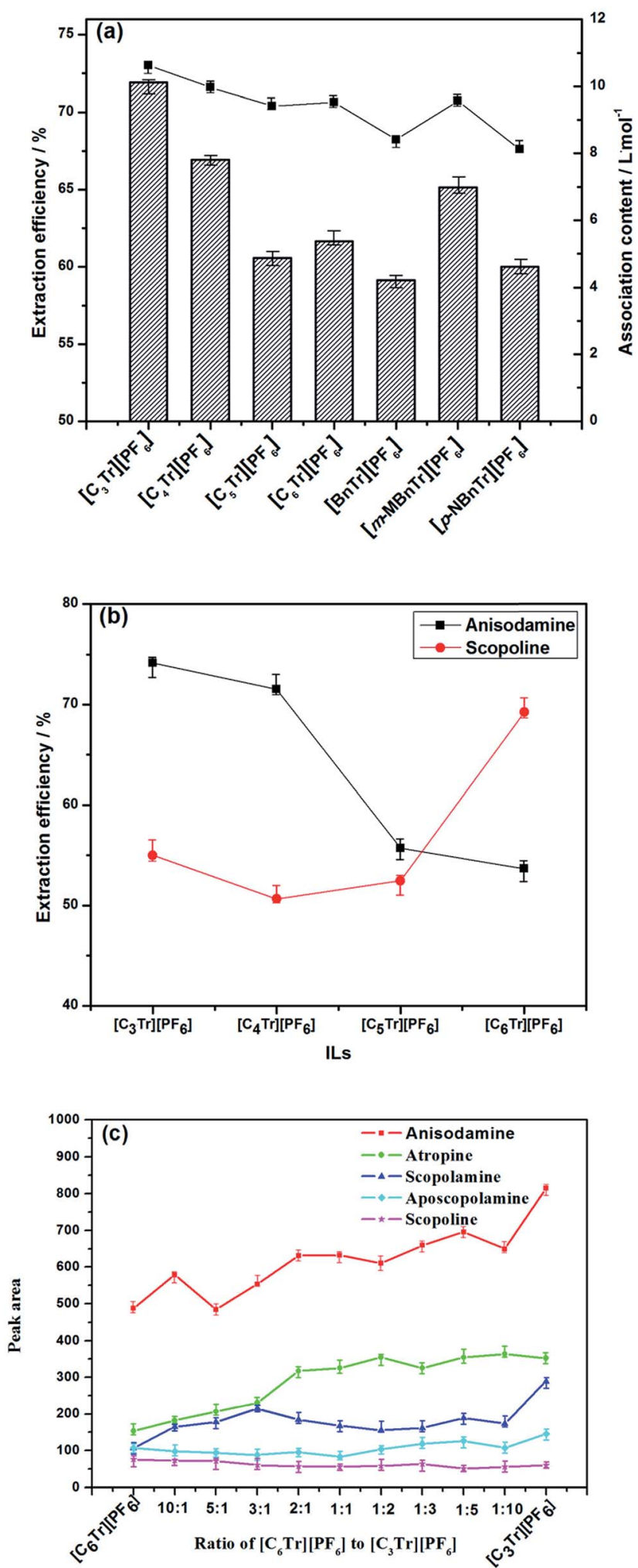

Fig. 3 The extraction efficiency of total alkaloids (a) and two main alkaloids (b) by ionic liquids aqueous solution and five tropane alkaloids using $\left[\mathrm{C}_{3} \operatorname{Tr}\right]\left[\mathrm{PF}_{6}\right]+\left[\mathrm{C}_{6} \operatorname{Tr}\right]\left[\mathrm{PF}_{6}\right]+\mathrm{H}_{2} \mathrm{O}$ ternary system as extraction solvents (c). interaction because of its small volume and hindrance, and related ILs have higher absolute value of Gibbs free energy of association $(\Delta G)$. When the carbon number is beyond 4 , the polarity effect will dominate the extraction process. As for the mixture of target alkaloids with different polarity (just like their coexisting status in herbal cells), those with higher polarity can raise the polarity level of total alkaloids, especially when they have superior quantity and content. So $\left[\mathrm{C}_{3} \mathrm{tr}\right]\left[\mathrm{PF}_{6}\right]$ aqueous solution has shown the highest extraction efficiency in seven types of ionic liquids for raw material of radix physochlainae.

Finally, there is little investigation and application of more than one ionic liquid in similar process in previous studies. Since the most ideal IL for the extraction of various individual alkaloids is different, here the possible synergistic effect of two kinds of ILs mixed solution was explored and the combination of $\left[\mathrm{C}_{3} \operatorname{Tr}\right]\left[\mathrm{PF}_{6}\right]-\left[\mathrm{C}_{6} \operatorname{Tr}\right]\left[\mathrm{PF}_{6}\right]$ was selected which possessed the highest and lowest polarity in the series of $\left[\mathrm{C}_{n} \operatorname{Tr}\right]\left[\mathrm{PF}_{6}\right]$ respectively. The experimental conditions are as follows: $0.1 \mathrm{~mol} \mathrm{~L}^{-1}$ ionic liquids mixture solution, $1: 10$ solid-liquid ratio, $50 \mathrm{~min}$ on $70^{\circ} \mathrm{C}$ for comparing single ionic liquids and IL mixture with the different ratios $\left(\left[\mathrm{C}_{6} \operatorname{Tr}\right]\left[\mathrm{PF}_{6}\right]:\left[\mathrm{C}_{3} \operatorname{Tr}\right]\left[\mathrm{PF}_{6}\right]=1: 0,10: 1,5: 1\right.$, $3: 1,2: 1,1: 1,1: 2,1: 3,1: 5,1: 10,0: 1, \mathrm{w} / \mathrm{w})$. As shown by the results in Fig. 3c, it can be found that the content of anisodamine will become higher with the increase of $\left[\mathrm{C}_{3} \mathrm{Tr}\right]\left[\mathrm{PF}_{6}\right]$ in the mixture, meanwhile the content of scopoline will decrease. On the other hand, the extraction performance of the mixture of $\left[\mathrm{C}_{6} \operatorname{Tr}\right]\left[\mathrm{PF}_{6}\right]$ and $\left[\mathrm{C}_{3} \operatorname{Tr}\right]\left[\mathrm{PF}_{6}\right]$ aqueous solution was always worse than that of $\left[\mathrm{C}_{3} \mathrm{Tr}\right]\left[\mathrm{PF}_{6}\right]$ aqueous solution and no synergistic effect was found. This result could be ascribed to the unavoidable association action between $\left[\mathrm{C}_{6} \operatorname{Tr}\right]\left[\mathrm{PF}_{6}\right]$ and $\left[\mathrm{C}_{3} \operatorname{Tr}\right]\left[\mathrm{PF}_{6}\right]$, which can result in their nonideal mixing and nonlinear variation of physico-chemical properties. ${ }^{24-26}$ It was not conducive to their interaction with alkaloid moleculars and improvement of extraction efficiency. Therefore, the following studies were carried out with $\left[\mathrm{C}_{3} \operatorname{Tr}\right]\left[\mathrm{PF}_{6}\right]$ as the extraction solvent.

\subsection{Effects of various conditions on the extraction of tropane alkaloids}

Concentration of ionic liquid solution has great influence on the swelling and destruction of cell wall together with mass transfer process of extraction solution, which can directly determine the extraction efficiency of extractant on the target alkaloids. In the following investigation, $10 \mathrm{~mL}$ of $0.05 \mathrm{~mol} \mathrm{~L}^{-1}$ $\sim 0.175 \mathrm{~mol} \mathrm{~L}^{-1}\left[\mathrm{C}_{3} \operatorname{Tr}\right]\left[\mathrm{PF}_{6}\right]$ aqueous solutions were compared in the extraction of $1.0 \mathrm{~g}$ herbal powders for $50 \mathrm{~min}$ at $70^{\circ} \mathrm{C}$. As shown in Fig. 4a, the extraction efficiency firstly increases and then gradually decreases with the increase of IL concentration. It is due to that with the continuous increase of concentration of ionic liquid, over high viscosity of extractant will hinder radix physochlainae powders to well disperse in the ionic liquid solution for full extraction and the permeation of the latter into plant cells together with mass transfer become more difficult. ${ }^{27}$

Extraction time is another important factor needed investigation and optimization. After reaching complete extraction, excessive time will be unnecessary and unfavorable due to the instability of ester bond or ether bond in the structures of 
Table 1 Association constant $\left(K_{\mathrm{A}}\right)$, limiting molar conductivity $\left(\Lambda^{\infty}\right)$ and Gibbs free energy of IL association $(\Delta G)$

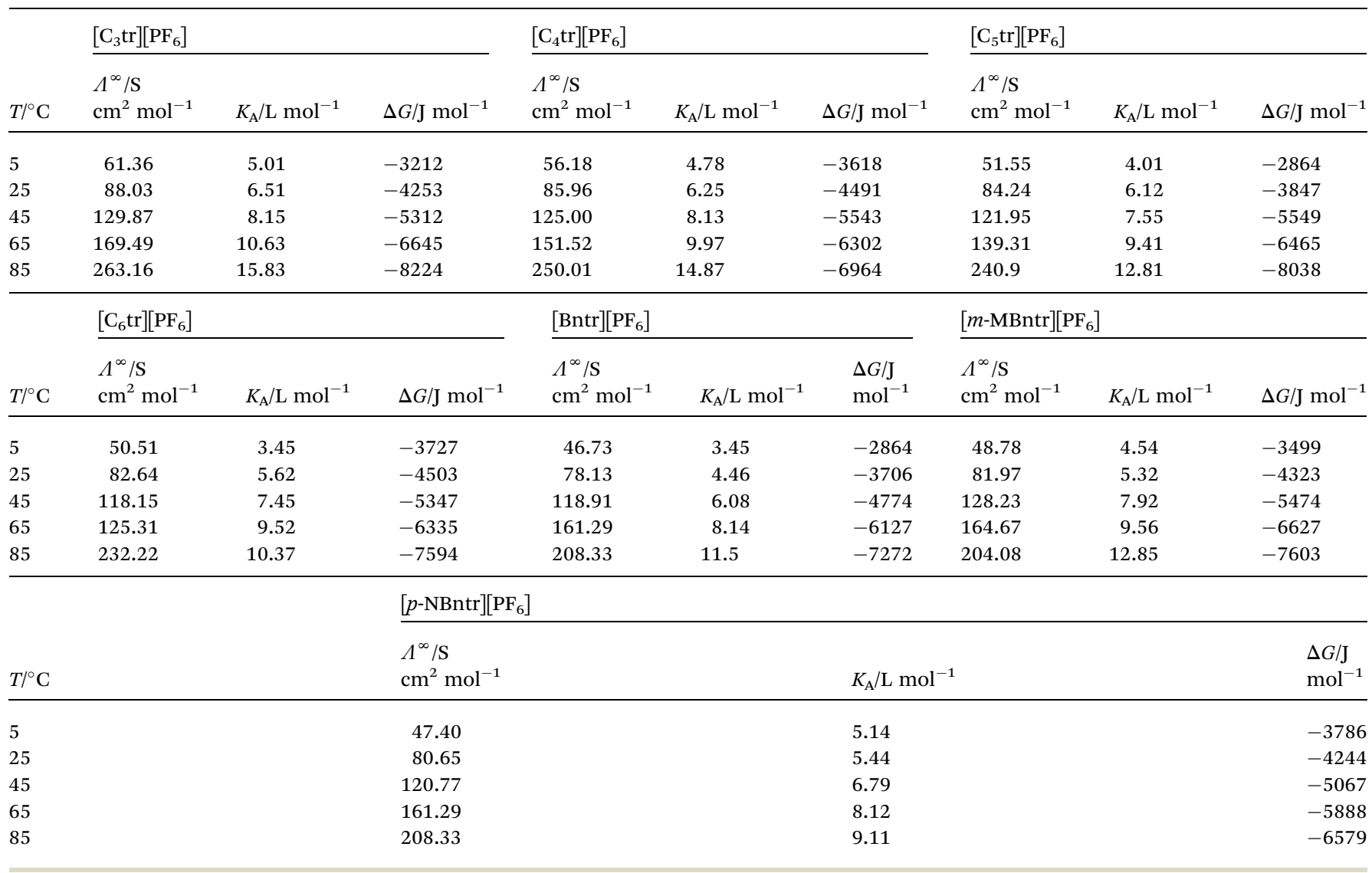

tropane alkaloids. In order to avoid possible decomposition and racemization of products in the solution, $1.00 \mathrm{~g}$ herbal powders were extracted with $10 \mathrm{~mL}$ of $0.05 \mathrm{~mol} \mathrm{~L}^{-1}\left[\mathrm{C}_{3} \mathrm{tr}\right]\left[\mathrm{PF}_{6}\right]$ aqueous solutions from 10 to $80 \mathrm{~min}$. It was found the complete extraction could be achieved within $50 \mathrm{~min}$ by heating in water bath (see Fig. 4b). The fast-growing stage of extraction efficiency was the first $20 \mathrm{~min}$; after $50 \mathrm{~min}$, it gradually increased and extraction process approached equilibrium state. In order to further analyze related stages, kinetics research will be performed in Section 3.5.1. Compared to other alkaloids extraction by water, ${ }^{28}$ it took less time for above ionic liquid aqueous solution to extract alkaloids from natural plants. Structural similarity makes them extract tropane alkaloids more easily from radix physochlainae in 'like dissolves like' mode.

Besides the concentrations of ionic liquids and extraction time, the solid-liquid ratio of the extraction system was also studied. Excessive ionic liquid will result in the increase of solvent consumption, and then increase the burden of IL recovery. Different ratios of liquid to solid $(40,30,20$ and $10 \mathrm{~mL} \mathrm{~g}^{-1}$ ) have been investigated and the extraction was carried out with $0.05 \mathrm{~mol} \mathrm{~L}^{-1}\left[\mathrm{C}_{3} \mathrm{tr}\right]\left[\mathrm{PF}_{6}\right]$ aqueous solution for 50 min on $70{ }^{\circ} \mathrm{C}$ (see Fig. 4c). The results indicated that the solid to liquid ratio grew fast in the range of $1: 10-1: 30$; in the range of $1: 30-1: 40$, extraction efficiency of tropane alkaloids was increased slowly and then unchanged. In the fast stage of extraction, the significant concentration difference inside and outside the cells can promote mass transfer and diffusion effectively, the equilibrium concentration will become lower and more alkaloids can be extracted when the volume of solvent system is greater; if the excessive IL solution is used, heat will be absorbed by the large amount of solvent and could not be exerted onto the herbal material in the second stage. ${ }^{28}$ The solid-liquid ratio of $1: 30$ is enough for complete extraction of tropane alkaloids in the radix physochlainae powders.

Finally, extraction temperature should be investigated because the thermal effect is the driving force when the object is completely dispersed into the extractive solution, which also determines the contact area and probabilities between the ionic liquid and the target alkaloids. The extraction efficiency is shown in Fig. 4d through the comparative experiments under different temperature of $40,50,60,70,80$ and $90^{\circ} \mathrm{C}$. It can be found that the increase of temperature is linearly proportional to the extraction amount of tropane alkaloids for incomplete dispersion in solution which can affect mass transfer at lower temperature in the range of $40-70{ }^{\circ} \mathrm{C}$; but in the range of $70-$ $90{ }^{\circ} \mathrm{C}$, a linearly proportional decline appears because of product instability on high temperature. ${ }^{29}$ In conclusion, the temperature around $70{ }^{\circ} \mathrm{C}$ should be more appropriate for the extraction of target compounds according to the data and figure. 

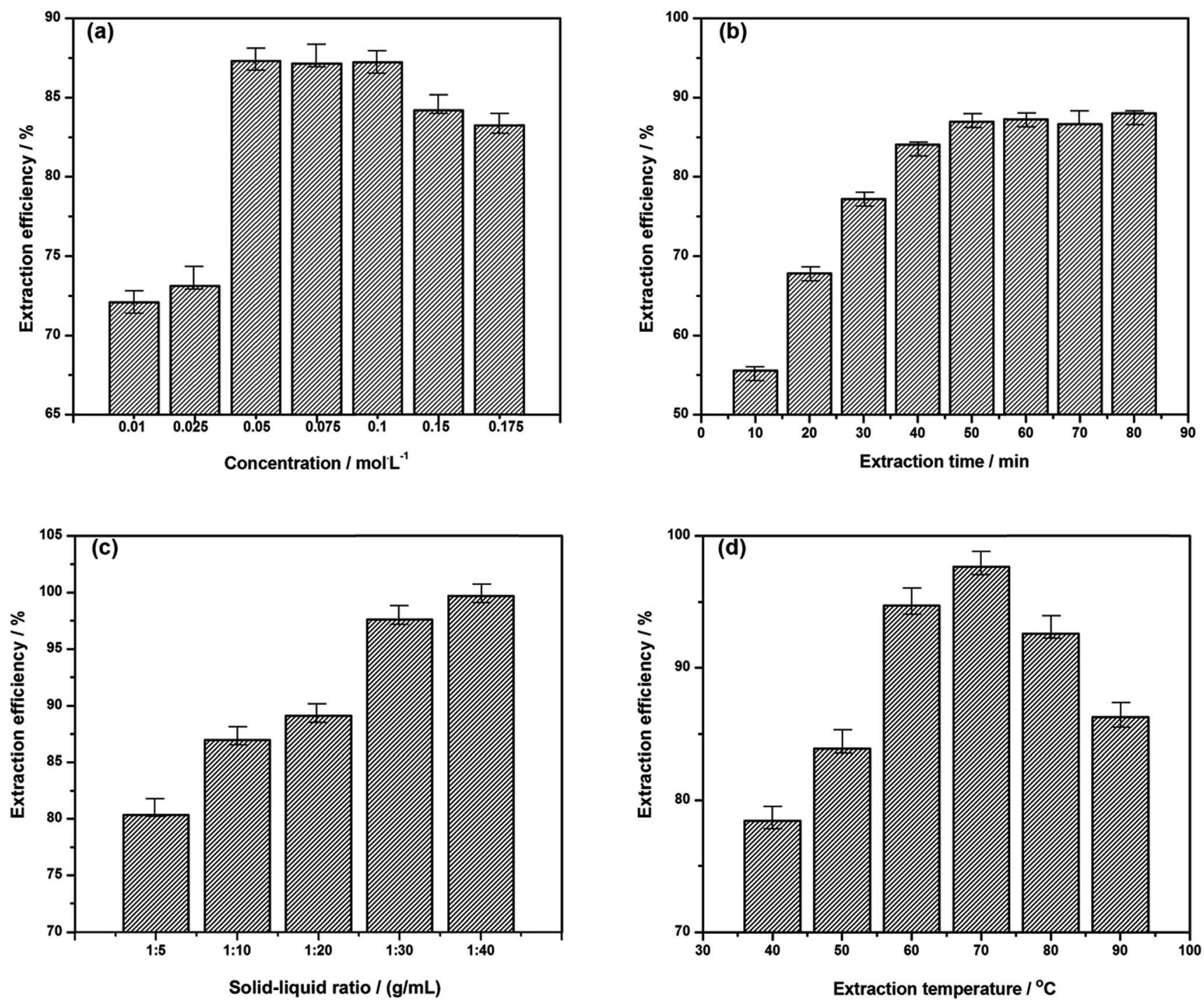

Fig. 4 Effects of various concentrations of ionic liquid (a), time (b), solid-liquid ratio (c) and temperature (d) on the extraction of total alkaloids.

\subsection{Central composite design for interaction analysis and optimization}

In order to further study the relationship among extraction factors and optimize extraction conditions, central composite design (CCD) was selected as the most commonly used method of response surface analysis. ${ }^{30}$ The experimental design was completed by Design Expert 7.0 on the basis of optimal extraction conditions, which was also used to analyze the results through response surface. Three related parameters were included for selection as various independent variables (each variable representing three levels). There was no obvious difference in the yield of alkaloids when the concentration of $\left[\mathrm{C}_{3} \mathrm{tr}\right]\left[\mathrm{PF}_{6}\right]$ from 0.05 to $0.1 \mathrm{~mol} \mathrm{~L}^{-1}$, so extraction time, solidliquid ratio and extraction temperature were selected which had more significant influence on the extraction efficiency. As the result, the regression second-degree complete model for the extraction efficiency $(Z, \%)$ in terms of coded factors is presented as the following equation:

$$
\begin{aligned}
Z= & 93.80+3.54 A+1.16 B+0.56 C+0.27 A B-0.19 A C \\
& +0.14 B C-1.50 A^{2}-2.54 B^{2}-2.68 C^{2}
\end{aligned}
$$

where $\mathrm{A}, \mathrm{B}$ and $\mathrm{C}$ represent solid-liquid ratio, extraction temperature and extraction time, respectively. The analysis results of response surface method are shown in ESI $1 \uparrow(\mathrm{RSM}$ optimization). The significance of each variable to the response value was judged by $F$ and $P$ values. It can be found that the response surface model is highly significant $(F=48.29$ and $P<$ $0.0001)$; at the same time, the lack of $F$ value of the model is 1.78 , which proves that the result is not significant and no missing factor in the regression equation. In addition, $A, B, C$, $A^{2}, B^{2}$ and $C^{2}$ are significant items. The analysis results of response surface method can prove the feasibility of the regression second-degree complete model. Furthermore, the credibility analysis of the regression equations also indicates the model can be used to predict the extraction results effectively. The coefficient of variation (C.V.) of the model is $0.73 \%$, which is in the acceptable range and shows good repeatability. 
In addition, the "Adj $R$-Squared" of 0.9638 and $R^{2}$ of 0.9841 indicate that the model can explain the change of $96.38 \%$ response value, and the fitting of the model can better reflect the actual situation. In summary, the optimal extraction efficiency of $95.1 \%$ can be obtained, the optimal extraction temperature was $75{ }^{\circ} \mathrm{C}$, the extraction time was $55 \mathrm{~min}$ and the best solid-liquid ratio was $1: 35$; meanwhile the final purity of total alkaloid reached $\mathbf{9 2 . 8 \%}$ under above optimized conditions, which proved the highly selective extraction of IL for 'like dissolves like' mechanism. Moreover, the influential order of the three variables is: solid-liquid ratio $(P<0.0001)>$ extraction temperature $(P=0.0016)>$ extraction time $(P=0.0479$, shown as $3 \mathrm{D}$ plots in ESI $1 \dagger)$, which can prove that the solid-liquid ratio plays a very crucial role in extraction.

\subsection{Comparison with traditional methods and recovery of alkaloids}

After exploring the optimal conditions, the extraction efficiency of alkaloids resulting from the developed method was compared with corresponding performance of other common solvents from previous research ${ }^{31}$ and Chinese Pharmacopoeia. In the following study, the system of $0.1 \%$ hydrochloric acidwater, $85 \%$ ethanol-water, and the system of $85 \%$ ethanol- $0.1 \%$ hydrochloric acid-water were compared with $0.05 \mathrm{~mol} \mathrm{~L}^{-1}$ $\left[\mathrm{C}_{3} \mathrm{Tr}\right]\left[\mathrm{PF}_{6}\right]$ aqueous solution. Because imidazolium ionic liquids with the same anion of $\left[\mathrm{PF}_{6}\right]^{-}$are hydrophobic and cannot be dissolved in water well, their performance was not compared with above systems. Instead, $0.05 \mathrm{~mol} \mathrm{~L}^{-1}$ [Bmim] $\left[\mathrm{BF}_{4}\right]$ was also selected in the list of solvents as a frequently-used imidazolium ionic liquid in extraction to validate the generalized 'like dissolves like' rule here. The traditional extraction was carried out with solid-liquid ratio of $1: 10$ on $70{ }^{\circ} \mathrm{C}$ for $50 \mathrm{~min}$. It should be noted that microwave or ultrasonic wave-assisted extraction was not considered in the study because they were found unfavourable for the selective extraction; although these methods can enhance mass transfer and shorten extraction time at some extent, they will lower the purity of products significantly $(<82 \%)$ according to our experiments. Even if $40 \mathrm{~Hz}$ ultrasonic wave was used in the extraction of tropane alkaloids, 75 min was still needed to extract them completely in previous study. ${ }^{5}$ On the basis of the comparison under the same conditions (see Fig. 5a), the extraction efficiency of tropane ionic liquid aqueous solution is highest; water shows the worse extraction performance for the investigated hydrophobic alkaloids, but a great difference can be observed after adding a little $\left[\mathrm{C}_{3} \mathrm{Tr}\right]\left[\mathrm{PF}_{6}\right]$ into water. However, when we used $[\mathrm{Bmim}]\left[\mathrm{BF}_{4}\right]$ instead of $\left[\mathrm{C}_{3} \mathrm{Tr}\right]\left[\mathrm{PF}_{6}\right]$, it was found the former could extract the alkaloids with higher polarity meanwhile those with lower polarity could not be extracted well, and total extraction efficiency became lower. Moreover, though ethanol also can improve the solubility of related objects in extraction system, its high concentration must be required and the extraction efficiency of $\left[\mathrm{C}_{3} \mathrm{tr}\right]\left[\mathrm{PF}_{6}\right]$-water still cannot be transcended by it. Meanwhile, the purity of total alkaloids extracted by ethanol was only $49.2 \%$, while the selective interaction from tropine-based IL makes the product purity reach $92.8 \%$ in new 'like (a)

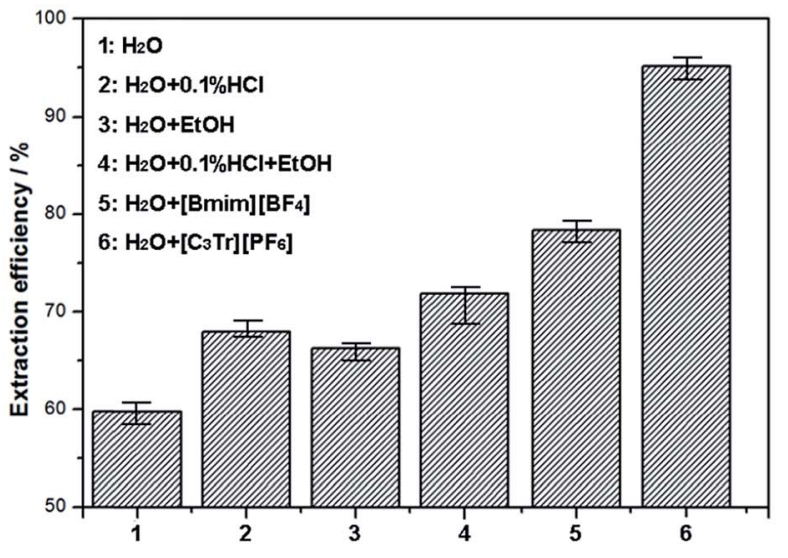

(b)

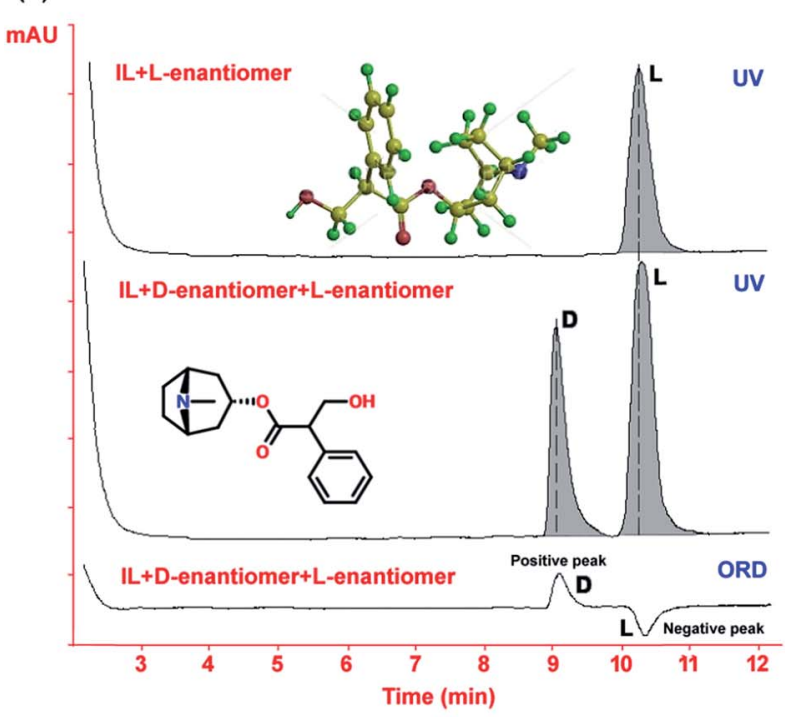

(c)

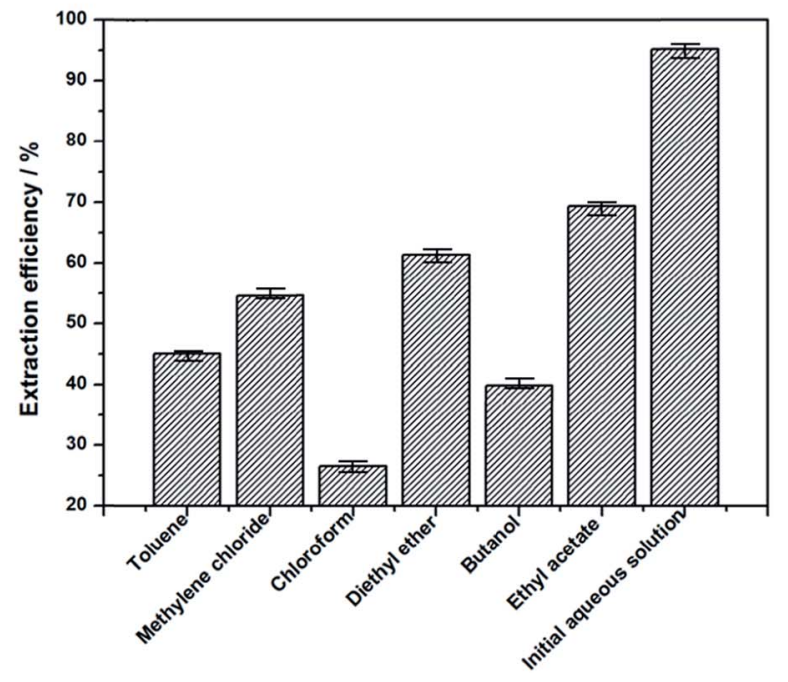

Fig. 5 Performance comparison of different extraction solvents on extraction efficiency (a), the chromatograms in racemization study by using chiral HPLC-UV/ORD (b) and the extraction efficiency of various solvents in recovery of tropane alkaloids (c). 
Table 2 Comparison of specific rotation with IL aqueous solution, scopolamine aqueous solution and scopolamine-IL aqueous solution

\begin{tabular}{llll}
\hline & {$[a]_{\lambda=598}{ }^{t}$} & & \\
\cline { 2 - 2 } Temperature $/{ }^{\circ} \mathrm{C}$ & $\begin{array}{l}\text { IL aqueous } \\
\text { solution }\end{array}$ & $\begin{array}{l}\text { Scopolamine } \\
\text { aqueous solution }\end{array}$ & $\begin{array}{l}\text { Scopolamine-IL } \\
\text { aqueous solution }\end{array}$ \\
\hline 25 & 0.18 & 29.00 & 28.00 \\
35 & 0.18 & 22.00 & 22.00 \\
70 & 0.06 & 16.00 & 13.00
\end{tabular}

dissolves like' mode. The extraction efficiency of $0.1 \%$ hydrochloric acid-water is not very ideal because the basicity of tropane alkaloids is not so strong that they cannot easily become water-soluble salt and fully extracted by this acidic aqueous solution. $\left[\mathrm{C}_{3} \operatorname{tr}\right]\left[\mathrm{PF}_{6}\right]$ belongs to near-neutral $\mathrm{IL}$, which will not rely on salifying process to realize extraction. Furthermore, though the unit price of ionic liquids is a little higher, its dosage is very small and can be efficiently reused after efficient recovery through the suitable method.

In addition, because target tropine alkaloids usually contain chiral center in their structures, they are optically active (e.g. atropine existing in natural plants with its L-configuration). The ester bond in their structures cannot be easily affected under weakly acidic and near-neutral conditions, and it is the most stable in the $\mathrm{pH}$ range of 3.5-4. However, in the process of traditional extraction, it is difficult to obtain their original configuration in the raw materials because the alkaline solution or the long extraction time will cause the racemization of target alkaloids. ${ }^{32,33}$ Alkaloids are often found in the form of their salts in herbs for their binding with coexisting acids. In the pretreatment process in Section 2.5.2, ammonia was frequently used to transform alkaloids from their ionic state to molecular state for ideal extraction result. How to eliminate influence of related conditions on the structure and configuration of target alkaloids was focused on by researchers in the past time. Considering the tropine-based ionic liquids were employed in the new developed extraction mentioned above, the off-line Autopol IV polarimeter (Rudolph Research Analytical, Hackettstown, USA) and on-line LC2000P optical detector (JASCO, Tokyo, Japan) coupled with HPLC were applied to observe the possible racemization phenomenon in the mixture of atropine$0.05 \mathrm{~mol} \mathrm{~L}^{-1}\left[\mathrm{C}_{3} \mathrm{tr}\right]\left[\mathrm{PF}_{6}\right]$ aqueous solution on $70{ }^{\circ} \mathrm{C}$ for $50 \mathrm{~min}$. The chromatographic analysis was performed on Chromtech Chiral-AGP column $(150 \mathrm{~mm} \times 2 \mathrm{~mm}$ I.D., $5 \mu \mathrm{m}$, Congleton, UK) at room temperature and mobile phase was composed of $1 \%$ acetonitrile- $10 \mathrm{mmol}$ aqueous ammonium acetate buffer (pH 5.8); UV detection wavelength was $230 \mathrm{~nm}$ and flow rate was controlled at $0.3 \mathrm{~mL} \mathrm{~min}{ }^{-1}$. Under these conditions, the samples of the mixture of $\mathrm{D}, \mathrm{L}$-atropine standard compounds and IL (as sample 1) together with the mixture of IL and L-atropine prepared above (as sample 2) were analyzed under the UV and ORD detection. As the result, no D-enantiomer appeared in the mixture after the L-atropine was mixed with $\left[\mathrm{C}_{3} \operatorname{tr}\right]\left[\mathrm{PF}_{6}\right]$ under extraction conditions (see Fig. 5b) and related off-line optical data in Table 2 also proved there was no racemization occurred
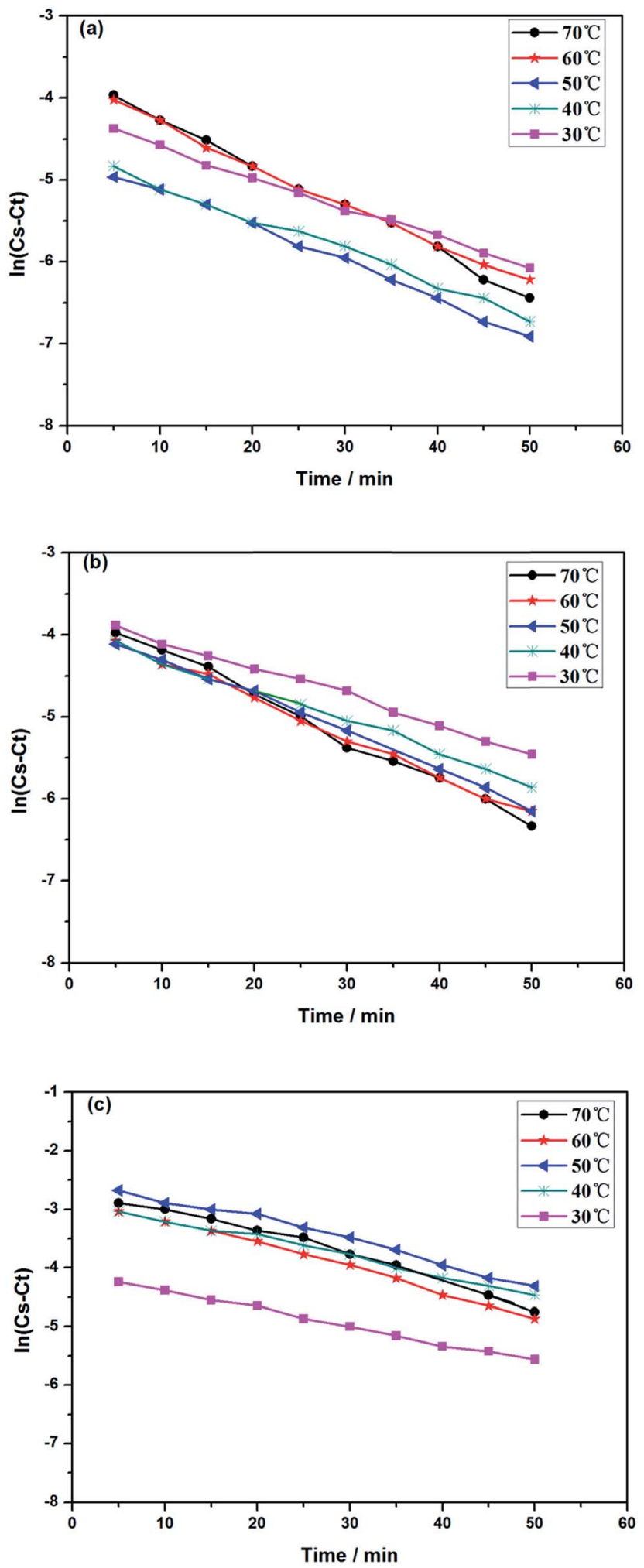

Fig. 6 Relationship between $\ln \left(C_{s}-C_{t}\right)$ and $t$ through different extraction solvents ((a) $0.05 \mathrm{~mol} \mathrm{~L}^{-1}\left[\mathrm{C}_{3} \mathrm{tr}\right]\left[\mathrm{PF}_{6}\right]$ aqueous solution, (b) $85 \%$ ethanol-water, (c) $0.1 \%$ hydrochloric acid-water).

in the solution. By comparison, the alkaline condition could result in the decomposition of ester bond and transformation of atropine configuration indeed. In summary, the developed 
method can not only realize the selective extraction efficiently, but also maintain the structure and configuration of products through specific intermolecular interactions.

Finally, considering the simplicity and efficiency of the method, the back extraction with common organic solvents (toluene, chloroform, dichloromethane, ethyl ether, $n$-butyl alcohol and ethyl acetate) was used to separate alkaloids from the ionic liquid and realize their recovery after the removal of water. These candidate solvents were mixed with the solid extract with solid-liquid ratio of $1: 3\left(\mathrm{~g} \mathrm{~mL}^{-1}\right)$ under stirring, respectively; then the organic solvent containing alkaloids was obtained by filtration and then concentrated under vacuum. Finally, the back-extracted products were dissolved in chromatographic methanol and analyzed by HPLC. The quantitative results in Fig. 5c indicate that the order of different solvents for alkaloids extraction efficiency is: chloroform $>n$-butyl alcohol $>$ dichloromethane $>$ toluene $>$ ethyl ether $>$ ethyl acetate. So chloroform was the best selection to recover alkaloids from their mixture with ILs. It is should be noted that, although VOS was used in above post-treatment process of extraction, its consumption was much less for the back extraction of solid product than that in back extraction of extracted solution or the direct extraction of herbal materials with chloroform (e.g. the authoritative method in China Pharmacopeia, solid-liquid ratio of radix physochlainae and chloroform is $1: 20, \mathrm{~g} \mathrm{~mL}^{-1}$ ), and here $1: 3$ was the ideal solid-liquid ratio of the solid extract and chloroform.

\subsection{Extraction mechanism and process analysis}

3.5.1 Kinetics of alkaloids extracted from radix physochlainae. The extraction rate constant $(\kappa)$ and kinetic order for heating extraction of alkaloids from radix physochlainae by ionic liquid aqueous solution and other organic solvents can be identified through the study of extraction kinetics. In this study, Abbe refractometer was used to measure the dynamic concentration of alkaloids in radix physochlainae according to the linear relationship between the refractive index and the solid concentration in the solution within the test range. ${ }^{34}$ Target alkaloids in $1.00 \mathrm{~g}$ of radix physochlainae powders with 60 mesh was extracted with $35 \mathrm{~mL} 0.05 \mathrm{~mol} \mathrm{~L}^{-1}\left[\mathrm{C}_{3} \mathrm{tr}\right]\left[\mathrm{PF}_{6}\right]$ aqueous solution, $85 \%$ ethanol-water and $0.1 \%$ hydrochloric acid-water, and the refractive index of samples was determined every five minutes within $1 \mathrm{~h}$. It is found that $\ln \left(C_{\mathrm{s}}-C_{t}\right)$ is linear with time $(t, \mathrm{~min})$ from Fig. 6 and Table 3. The results can indicate that the extraction kinetic equation derived from eqn (2) is in good agreement with the experimental results, and the dissolution process of alkaloids from radix physochlainae accords with the first-order kinetic model. The first-order kinetic model is obtained based on Fick's second law for linear diffusion when the $C_{t=0}$ of alkaloids is 0 , which is suitable for component extraction without decomposition and volatilization and the herbal particles with regular spheres. Zhao and his coworkers ${ }^{35}$ studied the extraction process of ester-series alkaloids from aconiti kusnezoffii Reichb in water bath and found that the kinetic equation could be well fit by the first-order kinetic model. In the study, extraction rate constant increased with the increase of temperature, and the results accorded with Fick's second law which showed that higher temperature resulted in the stronger penetration ability of solvents together with diffusion ability of those involved alkaloids. Similarly, the extraction rate constant $(\kappa)$ can also become greater with the increase of temperature when using $\left[\mathrm{C}_{3} \mathrm{tr}\right]\left[\mathrm{PF}_{6}\right]$ aqueous solution, $85 \%$ ethanol-water and $0.1 \%$ hydrochloric acid-water as extraction solvents, which can prove that high temperature is conducive to extract alkaloids from radix physochlainae. The order of extraction rate constant $(\kappa)$ with three kinds of solvents is: $\left[\mathrm{C}_{3} \mathrm{tr}\right]$ $\left[\mathrm{PF}_{6}\right]$ aqueous solution $>85 \%$ ethanol-water $>0.1 \%$ hydrochloric acid-water, because $\left[\mathrm{C}_{3} \mathrm{tr}\right]\left[\mathrm{PF}_{6}\right]$ can enter cells and interact with alkaloids with the same nucleus from radix physochlainae more easily than the others.

Furthermore, the fitting equation of $\ln \kappa$ and $1 / T$ had good linear relationship in the extraction of alkaloids, and the average activation energy $\left(E_{\mathrm{a}}\right)$ was calculated according to the linear equation in different solvents. The results were summarized in Table 3 , the average activation energy $\left(E_{\mathrm{a}}\right)$ of $\left[\mathrm{C}_{3} \operatorname{tr}\right]\left[\mathrm{PF}_{6}\right]$ aqueous solution was least which could prove that it was more easy to extract alkaloids from radix physochlainae, and the

Table 3 Regression equation of $\ln \left(C_{s}-C_{t}\right)$ and $t$ under different extraction solvents

\begin{tabular}{|c|c|c|c|c|c|}
\hline Extraction solvents & Temperature/K & Fitting equation & $R^{2}$ & $k / \min ^{-1}$ & $E_{\mathrm{a}} / \mathrm{kJ} \mathrm{mol}^{-1}$ \\
\hline \multirow[t]{5}{*}[\mathrm{C}_{3}\mathrm{tr}]{$\left[\mathrm{PF}_{6}\right]$ aqueous solution } & 303.15 & $\ln \left(C_{\mathrm{s}}-C_{t}\right)=-0.0371 t-4.2214$ & 0.9958 & 0.0371 & \multirow[t]{5}{*}{8.2178} \\
\hline & 313.15 & $\ln \left(C_{\mathrm{s}}-C_{t}\right)=-0.0402 t-4.6686$ & 0.9938 & 0.0402 & \\
\hline & 323.15 & $\ln \left(C_{\mathrm{s}}-C_{t}\right)=-0.0445 t-4.6732$ & 0.9964 & 0.0445 & \\
\hline & 333.15 & $\ln \left(C_{\mathrm{s}}-C_{t}\right)=-0.0490 t-3.8264$ & 0.9967 & 0.0490 & \\
\hline & 343.15 & $\ln \left(C_{\mathrm{s}}-C_{t}\right)=-0.0541 t-3.7104$ & 0.9963 & 0.0541 & \\
\hline \multirow[t]{5}{*}{$85 \%$ ethanol-water } & 303.15 & $\ln \left(C_{\mathrm{s}}-C_{t}\right)=-0.0346 t-3.7200$ & 0.9956 & 0.0346 & \multirow[t]{5}{*}{9.1792} \\
\hline & 313.15 & $\ln \left(C_{\mathrm{s}}-C_{t}\right)=-0.0380 t-3.9244$ & 0.9943 & 0.0380 & \\
\hline & 323.15 & $\ln \left(C_{\mathrm{s}}-C_{t}\right)=-0.0455 t-3.8419$ & 0.9974 & 0.0455 & \\
\hline & 333.15 & $\ln \left(C_{\mathrm{s}}-C_{t}\right)=-0.0471 t-3.8425$ & 0.9965 & 0.0471 & \\
\hline & 343.15 & $\ln \left(C_{\mathrm{s}}-C_{t}\right)=-0.0528 t-3.6729$ & 0.9952 & 0.0528 & \\
\hline \multirow[t]{5}{*}{$0.1 \%$ hydrochloric acid-water } & 303.15 & $\ln \left(C_{\mathrm{s}}-C_{t}\right)=-0.0300 t-4.0918$ & 0.9963 & 0.0300 & \multirow[t]{5}{*}{8.9923} \\
\hline & 313.15 & $\ln \left(C_{\mathrm{s}}-C_{t}\right)=-0.0321 t-2.8549$ & 0.9934 & 0.0321 & \\
\hline & 323.15 & $\ln \left(C_{\mathrm{s}}-C_{t}\right)=-0.0370 t-2.4380$ & 0.9879 & 0.0370 & \\
\hline & 333.15 & $\ln \left(C_{\mathrm{s}}-C_{t}\right)=-0.0413 t-2.7675$ & 0.9954 & 0.0413 & \\
\hline & 343.15 & $\ln \left(C_{\mathrm{s}}-C_{t}\right)=-0.0445 t-2.5018$ & 0.992 & 0.0445 & \\
\hline
\end{tabular}


average activation energy $\left(E_{\mathrm{a}}\right)$ was also lower than those reported values (e.g. $22.33 \mathrm{~kJ} \mathrm{~mol}^{-1}$ in previous study $\left.{ }^{35}\right)$. Meanwhile extraction rate constant of alkaloids extraction from radix physochlainae did not significantly change with temperature, so the temperature could not have important influence on the extraction efficiency of alkaloids according to the influential order of three variables (solid-liquid ratio, extraction temperature and time). The average activation energy $\left(E_{\mathrm{a}}\right)$ values of alkaloids extraction from radix physochlainae were below $20 \mathrm{~kJ} \mathrm{~mol}^{-1}$, indicating that this extraction process was controlled by diffusion. According to the previous study for the fitted $E_{\mathrm{a}}$ values of the solid-liquid extraction of bioactive compounds from natural products, when the activation energy value lay in the range between 20 and $40 \mathrm{~kJ} \mathrm{~mol}^{-1}$, indicating that the extraction process from herbal materials was governed by a mixed reaction and diffusion regime; and if the value was higher than $40 \mathrm{~kJ} \mathrm{~mol}^{-1}$, the process was controlled by the solubilization reaction. ${ }^{36}$

3.5.2 Effective diffusion coefficient. Effective diffusion coefficient $\left(D_{\mathrm{e}}\right)$ can reflect the diffusion ability of substances and depends mainly on the type of diffusion material and medium together with temperature and pressure. According to above study, the alkaloids concentration changed with time and corresponding moleculars diffused in an unstable state; accordingly; the diffusion behavior of related alkaloids accorded with Fick's second law. Furthermore, the diffusion coefficient $\left(D_{\mathrm{e}}\right)$ between liquid and solid phases was calculated according to eqn (5) by experimental study, and it can be observed from Table 4 that effective diffusion coefficient will increase with the rising temperature and has good linear relationship with temperature. This trend should be due to the mechanism that the infiltration, diffusion, dissolution of alkaloids molecules could be accelerated when the temperature became higher. On the other hand, extraction rate is proportional to the extraction temperature, the resistance of alkaloids delivering through the solid-liquid interface will be lowered when the solution viscosity reduces with the rise of temperature, which is the key to promote to extract alkaloids from radix physochlainae and improve the mass-transferring rate of alkaloids. It was found that the diffusion coefficient $\left(D_{\mathrm{e}}\right)$ of extraction by ionic liquid was higher than that in traditional solvents at every temperature, which proved that the extraction efficiency of alkaloids by ionic liquid was higher than $85 \%$ ethanol-water and $0.1 \%$ hydrochloric acid-water. The result was supported by the theory of 'like dissolves like' rule, and the tropane alkaloids are hydrophobic and easily dissolved because of selective interactions provided by the IL with similar structure. Moreover, it was easier to transfer alkaloids by using $85 \%$ ethanol-water than $0.1 \%$ hydrochloric acid-water for the tropane alkaloids were prone to dissolve in organic solvents. Consequently, the diffusion coefficient $\left(D_{\mathrm{e}}\right)$ in $85 \%$ ethanolwater was higher than that in $0.1 \%$ hydrochloric acid-water.

3.5.3 Thermodynamics of alkaloids extraction. The thermodynamic parameters of alkaloids from radix physochlainae are summarized in Table 5 . The positive value of the change in enthalpy $\left(\Delta H^{\circ}\right)$ indicates that the extraction of alkaloids from radix physochlainae is endothermic. The positive value of the change in entropy $\left(\Delta S^{\circ}\right)$ indicates the increase in disorder of the studied solid-liquid system due to the solute transfer from more ordered solid phase to the less ordered liquid phase. ${ }^{37}$ At the beginning of extraction, the target molecules were dispersed in plant cells and underwent two-dimensional movement; then they entered into the solvent system and moved in threedimensional space during continuous extraction. The negative values of change in Gibbs free energy $\left(\Delta G^{\circ}\right)$ indicate the extraction process to be spontaneous. ${ }^{38}$ Due to the subtle change of pressure and volume in the extraction process, the $\Delta H^{\mathrm{o}}$ value is approximately equal to the component extraction energy $\left(\Delta E^{\mathrm{o}}\right)$, which is absorbed by the system for extraction of target ingredients. Heating extraction of water bath is one way of heat transfer from outside to inside, and the ionic liquid can competitively form hydrogen bonds with hydroxyl groups on cellulose skeleton and affect the structure of plant cells, so the component extraction energy $\Delta E^{\mathrm{o}}$ of ionic liquid was higher than that of $85 \%$ ethanol-water and $0.1 \%$ hydrochloric acidwater. At the same time, the entropy $\left(\Delta S^{\circ}\right)$ will rise for the increase of randomness of moleculars. With the increase of temperature, the Gibbs free energy $\left(\Delta G^{\circ}\right)$ becomes slower,

Table 4 Values of $D_{\mathrm{e}}$ with different solvents and the exponential equation between $D_{\mathrm{e}}$ and $T$

\begin{tabular}{|c|c|c|c|c|}
\hline Extraction solvents & Temperature/K & Exponential equation & $R^{2}$ & $D_{\mathrm{e}} / 10^{-12}\left(\mathrm{~m}^{2} \min ^{-1}\right)$ \\
\hline \multirow[t]{4}{*}[\mathrm{C}_{3}\operatorname{tr}]{$\left[\mathrm{PF}_{6}\right]$ aqueous solution } & 303.15 & \multirow[t]{4}{*}{$10^{-12} D_{\mathrm{e}}=1.1417 \mathrm{e}^{0.0096 T}$} & \multirow[t]{4}{*}{0.9971} & 21.1089 \\
\hline & 313.15 & & & 22.8204 \\
\hline & 333.15 & & & 27.955 \\
\hline & 343.15 & & & 30.8075 \\
\hline \multirow[t]{3}{*}{$85 \%$ ethanol-water } & 303.15 & \multirow{3}{*}{$10^{-12} D_{\mathrm{e}}=0.8128 \mathrm{e}^{0.0106 T}$} & \multirow{3}{*}{0.9751} & 19.9678 \\
\hline & 333.15 & & & 27.3845 \\
\hline & 343.15 & & & 30.2370 \\
\hline \multirow[t]{4}{*}{$0.1 \%$ hydrochloric acid-water } & 303.15 & \multirow[t]{4}{*}{$10^{-12} D_{\mathrm{e}}=0.7312 \mathrm{e}^{0.0104 T}$} & \multirow[t]{4}{*}{0.9877} & 17.1153 \\
\hline & 313.15 & & & 18.2563 \\
\hline & 323.15 & & & 21.1089 \\
\hline & 333.15 & & & 23.3909 \\
\hline
\end{tabular}


Table 5 Thermodynamic parameters of alkaloids from radix physochlainae

\begin{tabular}{|c|c|c|c|c|c|}
\hline Extraction solvents & Temperature/K & $K_{\mathrm{e}}$ & $\Delta H^{\mathrm{o}} / \mathrm{kJ} \mathrm{mol}{ }^{-1}$ & $\Delta S^{\mathrm{o}} / \mathrm{J}(\mathrm{mol} \mathrm{K})^{-1}$ & $\Delta G^{\mathrm{o}} / \mathrm{kJ} \mathrm{mol}^{-1}$ \\
\hline \multirow{4}{*}[\mathrm{C}_{3}\operatorname{tr}]{$\left[\mathrm{PF}_{6}\right]$ aqueous solution } & 303.15 & 2.0461 & \multirow[t]{4}{*}{53.7965} & \multirow[t]{4}{*}{180.6594} & -0.9705 \\
\hline & 313.15 & 2.1862 & & & -2.7770 \\
\hline & 333.15 & 8.2589 & & & -6.3902 \\
\hline & 343.15 & 24.3876 & & & -8.1968 \\
\hline \multirow[t]{3}{*}{$85 \%$ ethanol-water } & 303.15 & 1.4382 & \multirow[t]{3}{*}{4.5703} & \multirow[t]{3}{*}{17.9579} & -0.8736 \\
\hline & 333.15 & 1.6650 & & & -1.4123 \\
\hline & 343.15 & 1.7551 & & & -1.5919 \\
\hline \multirow[t]{4}{*}{$0.1 \%$ hydrochloric acid-water } & 303.15 & 1.4620 & \multirow[t]{4}{*}{10.8986} & \multirow[t]{4}{*}{39.2689} & -1.0051 \\
\hline & 313.15 & 1.7852 & & & -1.3985 \\
\hline & 323.15 & 1.8603 & & & -1.7912 \\
\hline & 333.15 & 2.3060 & & & -2.1839 \\
\hline
\end{tabular}

which indicates that the entropy $\left(\Delta S^{\mathrm{o}}\right)$ increases more significantly than the enthalpy $\left(\Delta H^{\circ}\right)$. In conclusion, the extraction of alkaloids was entropy-driven. ${ }^{39}$

The thermodynamic parameters for extraction of alkaloids from radix physochlainae with traditional methods have not been reported before, here it can be found the equilibrium constant by $\left[\mathrm{C}_{3} \mathrm{tr}\right]\left[\mathrm{PF}_{6}\right]$ aqueous solution is higher than that in $85 \%$ ethanol-water and $0.1 \%$ hydrochloric acid-water. This result indicates that the solute transferring from the solid phase to liquid phase is more favorable by $\left[\mathrm{C}_{3} \operatorname{tr}\right]\left[\mathrm{PF}_{6}\right]$ aqueous solution. In addition, in comparison with other two traditional organic solvents, the change in entropy is higher when $\left[\mathrm{C}_{3} \mathrm{tr}\right]$ $\left[\mathrm{PF}_{6}\right]$ aqueous solution is used as extractive solvent. Hence tropane-series alkaloids are more feasible to be extracted by $\left[\mathrm{C}_{3} \mathrm{tr}\right]\left[\mathrm{PF}_{6}\right]$ aqueous solution than that by the other two conventional solvents on the basis of the change in Gibbs free energy in the extraction process with $\left[\mathrm{C}_{3} \mathrm{tr}\right]\left[\mathrm{PF}_{6}\right]$ aqueous solution, $85 \%$ ethanol-water and $0.1 \%$ hydrochloric acid-water.

3.5.4 Extraction process characterized by near infrared spectroscopy (NIR). Near infrared spectroscopy (NIR) has been widely used in many fields as one of useful analytical tools, especially for quantitative and qualitative analysis of traditional Chinese medicine. ${ }^{40,41}$ It has the advantages of high speed, convenience, accuracy and non-destruction, and online process monitoring can be easily realized with fiber spectrometer. In this section, the extraction process of alkaloids in $75^{\circ} \mathrm{C}$ water bath was monitored by NIR, and target system in $0.05 \mathrm{~mol} \mathrm{~L}^{-1}$ $\left[\mathrm{C}_{3} \mathrm{tr}\right]\left[\mathrm{PF}_{6}\right]$ aqueous solution after extraction for $0 \mathrm{~min} / 30 \mathrm{~min} /$ $55 \mathrm{~min}$ were analyzed. The probe with $2 \mathrm{~cm}$ optical length was selected and two optical fibers were used to transmit NIR radiation to a NIRQUEST512 spectrometer; the NIR spectra of extracts were collected when the integration time was $280 \mathrm{~ms}$ and the reference value of water solvent was stored as the background before the detection. Consequently, the NIR spectra are shown in ESI $2 \dagger$ and it can be found that the absorbance band of 1400-1500 $\mathrm{nm}$ increases gradually with the development of extraction, which belongs to the fragment of benzene ring in the structure of tropane alkaloids and indicates they are continuously extracted from radix physochlainae during this period. At the same time, the absorbance of $1500-$ $1600 \mathrm{~nm}$ also increases, which belongs to the characteristic area of hydroxyl groups. ${ }^{42}$ The increase of $-\mathrm{OH}$ concentration also can prove the gradual extraction of tropane alkaloids (containing more hydroxyls than $\left.\left[\mathrm{C}_{3} \mathrm{tr}\right]\left[\mathrm{PF}_{6}\right]\right)$ from radix physochlainae. Above two absorbance bands are the main characteristic regions for the process analysis of the studied extraction, which are ascribed to the major difference of related substituent groups in the structures of tropine-based IL and tropane-series alkaloids. They can be regarded as key observation points for on-line monitoring of this extraction process.

3.5.5 Analysis of herbal powders before and after extraction. In order to comprehensively investigate the extraction behavior in the studied process, FI-IR, SEM and TG were successively used to characterize the samples of radix physochlainae and its residue after extraction by ionic liquids. It can be found from the infrared spectrum (see Fig. 7a) that the wavenumber of main characteristic peaks remains unchanged basically and no new absorbance is generated, which indicates the extraction conditions are mild and tropane ILs cannot deconstruct or strongly combine with the cellulose fiber skeleton of herbal materials. So the coexisting impurities will become much less and ILs can be recovered easily. Meanwhile, compared with the sample before extraction, the absorption intensity of characteristic peak at $1400 \mathrm{~cm}^{-1}$ of $\mathrm{C}-\mathrm{N}$ bond becomes weak significantly. It can prove that most of tropane alkaloids in radix physochlainae have been selectively extracted by ionic liquids so that the absorbance of their characteristic functional groups disappears. On the other hand, it is obviously shown that the surface structure of radix physochlainae have changed after extraction through the SEM observation (see Fig. 7b). The surface of raw materials is relatively smooth, but the surface of residues after extraction becomes rough and porous. This cellular morphology resulting from IL is very beneficial for permeation and diffusion, and the improved mass transfer is closely related with high extraction efficiency. It is realized through the mechanism that the ionic liquid can competitively form hydrogen bonds with hydroxyl groups on cellulose and affect network of cellulose microfibril. ${ }^{43}$ According 


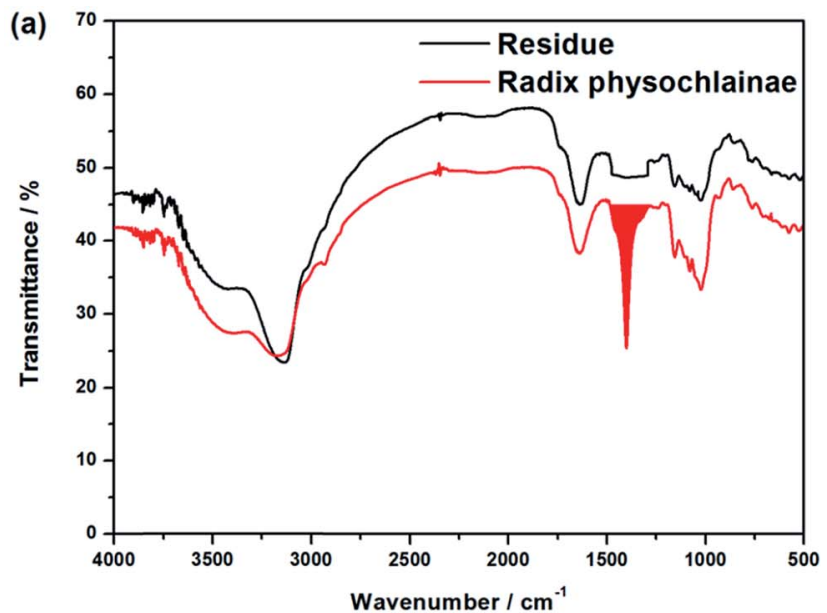

(b)
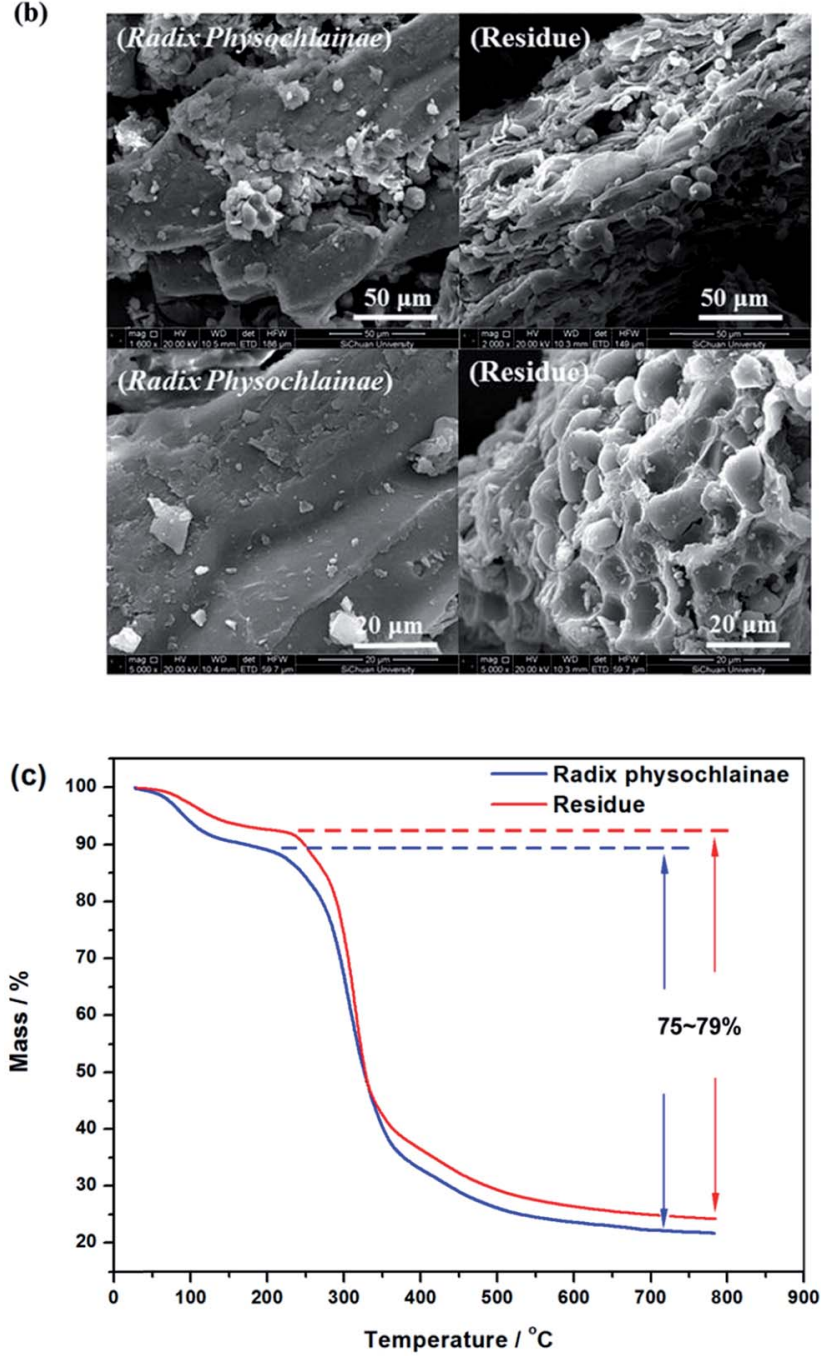

Fig. 7 FT-IR spectra (a), SEM images (b) and TG (c) of radix physochlainae and the extraction residue.

to the TG curves in Fig. 7c, it is found that glucose and fructose ${ }^{44}$ will decompose under $150{ }^{\circ} \mathrm{C}$ and the quality of glucose and fructose in herbal material is higher than that in its residue, so the result can be validated that bioactive compounds have been extracted from radix physochlainae powders. The thermal decomposition of the residue and radix physochlainae starts at $220{ }^{\circ} \mathrm{C}$, and there is a rapid devolatilization process from $300^{\circ} \mathrm{C}$ to $320^{\circ} \mathrm{C}$. The weight loss decreases gradually above $500{ }^{\circ} \mathrm{C}$, and the maximum weight loss is between $75 \%$ and $79 \%$ at the temperature of $700{ }^{\circ} \mathrm{C}$, which results from the decomposition of ionic liquids, cellulose and other coexisting constituents. The temperature of raw material and residue is around $300{ }^{\circ} \mathrm{C}$ and $320{ }^{\circ} \mathrm{C}$ on maximum mass loss-rate, respectively; it can be ascribed to that the pyrolysis temperature would shift to high temperature through extraction on high temperature. ${ }^{45}$

\section{Conclusions}

In this paper, the principle of 'like dissolves like' has been practiced through structural similarity between extractant and objects, and seven tropine-based ionic liquids were employed and compared with traditional solvents to extract tropane alkaloids from radix physochlainae, and the cations of ILs had significant influence on their prosperities together with extraction efficiency of alkaloids. $\left[\mathrm{C}_{3} \mathrm{tr}\right]\left[\mathrm{PF}_{6}\right]$ aqueous solution was found as the best extractant to achieve high extraction efficiency and purity simultaneously and there was no racemization of the alkaloids occurred in ionic liquid aqueous solution. So this kind of IL can not only realize the selective extraction efficiently, but also maintain the structure and configuration of products through specific intermolecular interactions as extraction solvent. At the same time, the extraction mechanism was tentatively studied through thermodynamic and kinetic analysis together with characterization of radix physochlainae and its residue with FI-IR, SEM and TG technology. It was found that the extraction of alkaloids from radix physochlainae was endothermic, the extraction process was spontaneous and alkaloids are more feasible to be extracted by $\left[\mathrm{C}_{3} \mathrm{tr}\right]\left[\mathrm{PF}_{6}\right]$ aqueous solution than $85 \%$ ethanol-water and $0.1 \%$ hydrochloric acid-water. In addition, a very small volume of chloroform was used to achieve the separation of involved compounds extracted in IL aqueous solution and tropane alkaloids could be easily extracted but ionic liquid did not. As the result, the hypothesis has been successfully proved in this study that the extractant with the same nucleus with objects should be more suitable and efficient in the extraction of the latter, which can be deemed as the generalized 'like dissolves like' theory.

\section{Conflicts of interest}

The authors declare no conflict of interest.

\section{Acknowledgements}

Preparation of this paper was supported by the National Natural Science Foundation of China (No. 81373284, 81673316). 


\section{References}

1 D. P. Yang and X. L. Zhang, Growth environment and present situations of thirteen kinds of wild Chinese medicinal materials in Henan province, J. Chin. Med. Mater., 1999, 22, 493-496.

$2 \mathrm{~K}$. Victor, Toxicological survey of African medicinal plants, Elsevier, Amsterdam, 4th edn, 2014.

3 T. H. Peng, S. S. Zhong, S. J. Zhang, X. P. Chen and F. Zeng, Comparative study on extractions of alkaloids from daturae flos by different methods, Chin. Tradit. Pat. Med., 2012, 34, 832-835.

4 T. H. Peng, Z. F. Zhao, S. J. Zhang, X. L. Huang and F. Zeng, The microwave-assisted extraction process of effective components of flos daturae, J. Guangzhou Univ. Tradit. Chin. Med., 2006, 23, 265-267.

5 J. G. Zhou, F. Liu, X. L. Xu, Y. Y. Liu, H. L. Peng, H. P. Wang and P. Luo, Optimization of microwave-assisted extraction of total alkaloids from semen strychni, J. Food Sci., 2010, 31, 116-119.

6 J. P. Hallett and T. Welton, Room-temperature ionic liquids: solvents for synthesis and catalysis, Chem. Rev., 2011, 111, 3508-3576.

7 J. H. Davis, Task-Specific Ionic Liquids, Chem. Lett., 2004, 33, 1072-1077.

8 M. J. Trujillo-Rodriguez, P. Rocio-Bautista, V. Pino and A. M. Afonso, Ionic liquids in dispersive liquid-liquid microextraction, Trends Anal. Chem., 2013, 51, 87-106.

9 D. T. Ho, C. Zhang, L. W. Hantao and J. L. Anderson, Ionic liquids in analytical chemistry: fundamentals, advances, and perspectives, Anal. Chem., 2014, 86, 262-285.

$10 \mathrm{X}$. Cao, X. Ye, Y. Lu, Y. Yu and W. Mo, Ionic liquid-based ultrasonic-assisted extraction of piperine from white pepper, Anal. Chim. Acta, 2009, 640, 47-51.

11 W. Y. Ma, Y. B. Lu, R. L. Hu, J. H. Chen, Z. Z. Zhang and Y. J. Pan, Application of ionic liquids based microwaveassisted extraction of three alkaloids $\mathrm{N}$-nornuciferine, $\mathrm{O}$ nornuciferine, and nuciferine from lotus leaf, Talanta, 2010, 80, 1292-1297.

12 L. Yang, H. Wang, Y. G. Zu, C. Zhao, L. Zhang, X. Chen and Z. Zhang, Ultrasound-assisted extraction of the three terpenoidindole alkaloids vindoline, catharanthine and vinblastine from Catharanthus roseus using ionic liquid aqueous solutions, Chem. Eng. J., 2010, 172, 705-712.

13 J. Lu, H. Song, Y. Yang, G. F. Qian, L. R. Nie and S. Yao, Synthesis and characterization of novel hexafluorophosphate salts with tropine-type cations, J. Mol. Liq., 2015, 209, 648-656.

14 R. Pardo, M. Zayat and D. Levy, ET (33) dye as a tool for polarity determinations: application to porous hybrid silica thin-films, J. Photochem. Photobiol., A, 2010, 210, 17-22.

15 S. H. Li, C. Y. He, H. W. Liu, K. A. Li and F. Liu, Ionic liquidbased aqueous two-phase system, a sample pretreatment procedure prior to high-performance liquid chromatography of opium alkaloids, J. Chromatogr. B: Anal. Technol. Biomed. Life Sci., 2005, 826, 58-62.
16 G. F. Chen, G. Y. Hu and A. G. Liu, Determination of total alkaloids in radix physochlainae by acid dye, Chin. Med. Mat., 1988, 11, 35-36.

17 Y. L. Zhang, H. L. Fu, C. C. Lu, M. J. Liu, J. Y. Zhou and Q. J. Fan, Extraction of rutin in Flos Sophorae by internal boiling and its kinetic and thermodynamic studies, Chin. Tradit. Pat. Med., 2015, 37, 895-898.

18 W. Wang, Q. Y. Li, Y. H. Liu and B. B. Chen, Ionic liquidaqueous solution ultrasonic-assisted extraction of three kinds of alkaloids from Phellodendron amurense Rupr and optimize conditions use response surface, Ultrason. Sonochem., 2105, 24, 13-18.

19 Y. Tao, Z. Zhang and D. W. Sun, Kinetic modeling of ultrasound-assisted extraction of phenolic compounds from grape marc: influence of acoustic energy density and temperature, Ultrason. Sonochem., 2014, 21, 1461-1469.

$20 \mathrm{H}$. Schwartzberg, Mathematical analysis of solubilization kinetics and diffusion in foods, J. Food Sci., 1975, 40, 211213.

21 S. Meziane and H. Kadi, Kinetics and thermodynamics of oil extraction from olive cake, J. Am. Oil Chem. Soc., 2008, 85, 391-396.

22 L. Li, S. T. Yu, C. X. Xie, F. S. Liu and H. J. Li, Synthesis of glycerol triacetate using functionalized ionic liquid as catalyst, J. Chem. Technol. Biotechnol., 2009, 84, 1649-1652.

23 A. R. Harifi-Mood, M. Aryafard, B. Minoofar and A. ZiyaeiHalimehjani, Specific spectroscopic behavior of Reichardt's betaine dye in binary mixtures of tetra- $n$-butylammonium glycinate and tetra- $n$-butylammonium L-alaninate with molecular solvents, J. Mol. Liq., 2014, 197, 315-321.

24 H. Ning Hui, M. Q. Hou, D. Z. Yang, X. C. Kang and B. X. Han, Ionic association in binary ionic liquids by conductivity, Acta Phys.-Chim. Sin., 2013, 29, 2107-2113.

25 K. Dong, Y. T. Song, X. M. Liu, W. G. Cheng, X. Q. Yao and S. J. Zhang, Understanding structures and hydrogen bonds of ionic liquids at the electronic level, J. Phys. Chem. B, 2012, 116, 1007-1017.

26 Q. G. Zhang, Y. Wei, S. S. Sun, C. Wang, M. Yang, Q. S. Liu and Y. A. Gao, Study on thermodynamic properties of ionic liquid n-butyl-3-methylpyridinium bis(trifluoromethylsulfonyl)imide, J. Chem. Eng. Data, 2012, 57, 2185-2190.

27 K. R. Seddon, A. Stark and M. Torres, Influence of chloride, water, and organic solvents on the physical properties of ionic liquids, Pure Appl. Chem., 2000, 72, 2275-2287.

28 Y. F. Jia and Z. Z. Zhang, Technics optimization of total alkaloid extraction from Phellodendron amurense, $J$. Jinggangshan Univ., 2010, 31, 112-117.

29 M. Li, G. Y. Zhang and G. X. Pan, Study on stability of aconite alkaloid, J. Liaoning Univ. Tradit. Chin. Med., 2014, 16, 52-55.

30 A. F. M. Cláudio, A. M. Ferreira, M. G. Freire and J. A. P. Coutinho, Enhanced extraction of caffeine from guarana seeds using aqueous solutions of ionic liquids, Green Chem., 2013, 15, 2002-2010.

31 J. L. Shen, L. S. Sun, F. Li, Y. Q. Guo, P. Xiao and Z. H. Tang, Research on the extraction of total alkaloids from Uncaria plant, J. Anhui Agric. Sci., 2010, 38, 357-358. 
32 J. Marin-Saez, R. Romero-Gonzalez and A. G. Frenich, Enantiomeric determination and evaluation of the racemization process of atropine in Solanaceae seeds and contaminated samples by high performance liquid chromatography-tandem mass spectrometry, J. Chromatogr. A, 2016, 1474, 79-84.

33 G. Blaschke, E. Lamparter and J. Schluter, Racemization and hydrolysis of tropic acid alkaloids in the presence of cyclodextrin, Chirality, 1993, 5, 78-83.

34 J. G. Li, J. X. Zhu, H. L. Shao and X. C. Hu, Rapid determination of regenerated silk fibroin aqueous solution concentration using refractive index, Liaoning Tussah Silk, 2006, vol. 3, pp. 4-6.

35 P. G. Zhao, J. Y. Song, C. H. Yu, X. Y. Dai and Y. L. Yan, Kinetics on extraction of ester-series alkaloids from aconiti kusnezoffii Reichb, Chin. J. Biochem. Pharm., 2012, 33, 52-54.

36 L. Lazar, A. L. Talmciu, I. Volf and V. I. Popa, Kinetic modeling of the ultrasound-assisted extraction of polyphenols from Piceaabies bark, Ultrason. Sonochem., 2016, 32, 191-197.

37 H. J. Fan, G. X. Lin, X. H. Xiao and G. K. Li, Study on the mechanism of microwave assisted extraction of active components from Lycoris radiata and Polygonum cuspidatum, Chem. J. Chin. Univ., 2006, 27, 2271-2276.

38 X. H. Yu, H. H. Chen, X. W. Huang, N. N. Jing, J. B. Chen and H. J. Fan, Effect of microwave irradiation on extraction of matrine from Sophora flavescens and investigation of its kinetic and thermodynamic mechanism, Acad. J. Guangdong Coll. Pharm., 2010, 27, 260-263.
39 R. C. A. Amarante, P. M. Oliveira, F. K. Schwantes and J. A. Moron-Villarreyes, Oil extraction from castor cake using ethanol: kinetics and thermodynamics, Ind. Eng. Chem. Res., 2014, 53, 6824-6829.

40 Y. Dou, Y. L. Ren, L. R. Teng and Y. Liang, Nondestructive quantitative analysis of cimetidine tablets using artificial neural networks in near-infrared spectroscopy, Spectrosc. Lett., 2005, 38, 1-11.

41 W. Fountain, K. Dumstorf, A. E. Lowell, R. A. Lodder and R. J. Mumper, Near-infrared spectroscopy for the determination of testosterone in thin-film composites, $J$. Pharm. Biomed. Anal., 2003, 33, 181-189.

42 E. Stark and K. Luchter, Near-infrared analysis (NIRA)a technology for quantitative and qualitative-analysis, Appl. Spectrosc. Rev., 1986, 22, 335-399.

43 M. G. Bogdanov and I. Svinyarov, Ionic liquid-supported solid-liquid extraction of bioactive alkaloids. II. Kinetics, modeling and mechanism of glaucine extraction from Glaucium flavum Cr. (Papaveraceae), Sep. Purif. Technol., 2013, 103, 279-288.

44 Y. L. Wang, Y. J. Sun and H. Y. Chen, Analysis of pyrolysis characteristics of Codonopsis, Chin. J. Tradit. Med. Sci. Technol., 2010, 17, 525-526.

45 K. Sjostrom, G. Chen, Q. Yu, C. Brage and C. Rosen, Promoted reactivity of char in co-gasification of biomass and coal: synergies in the thermochemical process, Fuel, 1999, 78, 1189-1194. 